\title{
Collusive Networks in Market Sharing Agreements in the Presence of an Antitrust Authority
}

\author{
Flavia Roldán* \\ Universidad Carlos III de Madrid ${ }^{\dagger}$
}

\begin{abstract}
This paper studies how the presence of an antitrust authority affects market-sharing agreements made by firms in oligopolistic markets. These agreements prevent firms from entering each other's market. The set of market-sharing agreements defines a collusive network, which is under suspicion by antitrust authorities. This paper shows that, from the firm's point of view, the probability of being caught is endogenous and depends on the agreements each firm has signed. Stable collusive networks can be decomposed into a set of isolated firms and complete alliances of different sizes. While in the absence of the antitrust authority, a network is stable if its alliances are large enough, when the antitrust authority is considered, the network is stability depends on the network configuration as a whole. Antitrust laws may have a pro-competitive effect as they give Firms in large alliances more incentives to cut their agreements at once.
\end{abstract}

JEL Classification: D43, K21, L41

Keywords: market-sharing, economic networks, antitrust authority, oligopoly.

* I am grateful to Antonio Cabrales and Luis Ubeda for their advice, guidance and support. I have greatly benefited from comments and useful suggestions from Natalia Fabra, Carlos Ponce and José Penalva. I thank seminar participants at the Student Workshop in Universidad Carlos III, the 2007 EARIE Meetings (Valence, Spain), XXXII Simposio de Análisis Económico, BBVA, University of Vienna, IESE Business School, Universitat de les Illes Balears. The usual disclaimers apply.

$\dagger$ Address for Correspondence: Flavia Roldán: Department of Economics, Universidad Carlos III de Madrid, Calle Madrid 126, 28903 Getafe, Spain, E-mail: faroldan@eco.uc3m.es. 


\section{Introduction}

Reciprocal market-sharing agreements between firms are agreements by which firms divide up a market and agree not to enter each other's territory. These agreements are under suspicion by antitrust authorities; moreover, if after an investigation, the antitrust authority finds proof of market-sharing agreements, the firms involved are penalized. It is the set of these bilateral agreements that gives rise to a collusive network among firms.

The goal of the present article is to study how the presence of an antitrust authority affects the market-sharing agreements made by firms. In particular, I examine the network structure that arises when each firm takes into account the possible penalty that exists when a new agreement is signed.

Market-sharing agreements are perennial problems in antitrust policy. As an example, in 1898, a group of iron pipe producers in the Mid-Western and the Western in United States rigged prices on some markets and reserved some cities as exclusive domains of one of the sellers. This was the Addyston Pipes Case (Scherer and Ross (1990)). More than one hundred years later, in January 2005, related to the case of the MCAA (Monochloroacetic Acid) chemicals cartel, the European Competition Commissioner stated "...the Commission cannot and will not tolerate price fixing and market-sharing. I will not allow companies to carve up the Single Market amongst themselves and so deny customers the benefits to which they are entitled..."

Antitrust authorities have been particularly concerned about the potential harm of market-sharing agreements and have spent substantial time and effort attempting to deter them. As a recent example in Europe, it is possible to mention the lifts and escalators cartel operating in Belgium, Germany, Luxembourg and the Netherlands. In February 2007, the European Commission fined the members of the cartel over $€ 990$ million. Between 1995 and 2004, the companies in the cartel shared markets among other anti-competitive practices.

However, not only do transnational competition authorities devote efforts to discourage this practice but national competition authorities also attempt to avoid it. For example, in 1999, the Irish Competition Authority issued cartel guidelines with the mission "to promote greater competition...by tackling anti-competitive practices, thereby contributing to an improvement in economic welfare". Particularly, it points out two types of arrangements: 1) the price-fixing cartel and 2) the market-sharing cartel.

Additionally, as another very recent example, we can point to the saving bank cartel operating in the Basque Country and in Navarra in Spain. In October 2007, the Spanish Competition Authority (Comisión Nacional de la Competencia) fined the saving banks BBK, 
Kutxa, Caja Vital and Caja Navarra over $€ 24$ million (the second highest fine imposed by the Spanish Competition Authority). Between 1990 and 2005, the cartel's members had agreed to carve up markets. So that, none of the saving banks in the cartel opened any branch in the each other's "traditional" territory (while conducting a remarkable territorial expansion in other provinces, especially near the borders).

Therefore, market-sharing cartels are a current problem in antitrust policy and, as we have seen, the antitrust authorities devote considerable effort to avoiding them. This point stresses the importance of understanding how the collusive agreements work and how they interact with the policy that has tried to deter them in order to promote and develop a healthy economy. This is the aim of this paper.

In particular, we assume that each firm is associated to one market, i.e., its home market. In spite of this, each firm can enter and compete in all foreign markets. Market-sharing agreements are modeled as bilateral or reciprocal agreements whereby firms commit to staying out of each other's market. The set of these reciprocal agreements gives rise to a collusive network among firms.

The antitrust authority is defined by a probability of inspection and by a fine which is imposed on firms that are proved guilty of market-sharing agreements. The fine is equal to the firm's limited liability, which is assumed equal to the firm's total profits.

We first study the actual probability of being discovered in the collusive network framework. We show that the probability of being caught depends on the agreements each firm has signed. That is, the probability of firm $i$ being detected depends not only on whether firm $i$ is inspected by the antitrust authority but also on whether any firm that has formed an agreement with $i$, is inspected. Therefore, if a firm is inspected and a market-sharing agreement exists, then it is detected, and the firms involved in it are penalized. However, the firm in consideration might be detected without being inspected because any firm that has an agreement with it was inspected.

We then provide a characterization of the stable network under the presence of the antitrust authority. We show that the pairwise stable network can be decomposed into a set of isolated firms and complete components of different sizes. While in the absence of the antitrust authority a network is stable if its alliances are large enough, when the antitrust authority is considered, the network's stability depends on the network configuration as a whole. To understand this, the following observation is crucial. If the antitrust authority detects a market-sharing agreement between two firms, then it will punish each firm with a fine equal to the total profits that each firm ends up having. Thus, when considering whether or not to enter into a market-sharing agreement, the firm must take into account that if it is detected by the antitrust authority, it will lose not only the profits in its own market, but also the profits in those markets in which the firm is not colluding.

This implies that the lower bound on the size of complete components depends on each 
network configuration, and on each probability of inspection. Additionally, that lower bound may be greater than the lower bound in the absence of the antitrust authority. Nevertheless, the set of isolated firms may enlarge. We conclude that under the presence of the competition authority, more structures that are competitive can be sustained through bilateral agreements.

Furthermore, when a strong stability notion is considered, the antitrust authority has a pro-competitive impact. That is, as the probability of inspection increases, firms in large components have more incentives to renege on all their agreements at once, and it might lead to break-down collusion.

This article brings together elements from the literature of market-sharing agreements, networks, and law enforcement. We study a particular way of collusion: market-sharing agreements; and these collusive agreements have a key feature: they are bilateral agreements. Therefore, we borrow from the Network literature and the Collusion literature.

Networks is currently a very active field of research. Prominent contributions to this literature include, among others, Jackson and Wolinsky (1996), Goyal (1993), Dutta and Mutuswami (1997) and Jackson and van den Nouweland (2005). In particular, in the first, the formation and stability of social networks are modeled when agents choose to maintain or destroy links using the notion of pairwise stability. We follow Jackson and Wolinsky (1996) and Jackson and van den Nouweland (2004) to characterize the stable and the strongly stable networks.

Besides these theoretical articles, there is also more and more literature that applies the theory of economic networks to models of oligopoly. Among others, Goyal and Joshi (2003), Goyal and Moraga (2001), and Belleflamme and Bloch (2004). The first two are related to the formation of bilateral agreement in order to reduce costs. Belleflamme and Bloch (2004) is closely related to the current work. They have analyzed the collusive network of market-sharing agreements among firms, but they do not take into account the existence of antitrust authorities. Therefore, their results may be limited under those circumstances. They find that, in a stable network, there exists a unique lower bound in the size of complete components. Moreover, when that unique threshold is equal to 1, the set of isolated firms is composed, at most, by only one firm. These results are in contrast with ours. Under the presence of the antitrust authority, we are not able to define that lower bound and, ultimately, this fact implies that more competitive structure are possible to sustain in such case.

On the other hand, network and crime is another application of network economics. Two recent papers related with the present article are Calvó-Armengol and Zenou (2003) and Ballester, Calvó-Armengol, and Zenou (2006)

Calvó-Armengol and Zenou (2003) study the impact of the network structure, and its geometric details, on individual and aggregate criminal behavior. Specifically, they provide 
a model of networks and crime, where the expected cost to commit criminal offenses is shaped by the network of criminal mates. Ballester, Calvó-Armengol, and Zenou (2004, 2006) further develop this approach. As main results, they relate individual equilibrium outcomes to the players' positions in the network and also characterized an optimal network-based policy to disrupt the crime. In these papers, the network formation game is analyzed. This approach is different from ours. That is, we dispense with the specifics of the noncooperative game and we model a notion of what is stable (a fixed network approach). The other difference is the kind of externalities that one link entails. In both papers, the competition among criminals by the booty acts as a negative externality. However, they assume that the criminal connections transmit to players (criminals) the necessary skill to undertake successful criminal activities. Specifically, the higher the criminal connections, the lower is the individual probability of being caught. Moreover, these are in sharp contrast with our assumptions about the externalities of signing a new agreement. Namely, we assume that more agreements increase the "booty" as long as the individual profits are a decreasing function in the number of active firms in the market (positive externality). By contrast, each link entails a negative externality. As the number of agreements increases, the probability of being discovered also increases. Furthermore, the penalty is also positively related with the number of agreements. Therefore, one more agreement increases the expected fine imposed by the competition authority.

Regarding the Collusion literature, after the seminal contribution of Stigler (1950) the stability of the price-fixing cartel has been extensively studied. For an excellent reference of this literature see Vives (2001).

As we have said before, the main goal of this article is to explore the impact of the antitrust authority on the collusive network's structure. In the vast literature of antitrust enforcement, the following papers, among others, study the effect of antitrust policy on cartel behavior. Block et al. (1981) is the first systematic attempt to estimate the impact of antitrust enforcement on horizontal minimum price fixing. Their model explicitly considers the effect of antitrust enforcement on the decision of firms within an industry to fix prices collusively. They show that a cartel's optimal price is an intermediate price (between the competitive price and the cartel's price in absence of antitrust authority) and this intermediate price depends on the levels of antitrust enforcement efforts and penalties.

Besanko and Spulber (1989), and Besanko and Spulber (1990) with a different approach, use a game of incomplete information where the firms' common cost is private information and neither the antitrust authority nor the buyers observe the cartel formation. Instead, they draw inferences from the observed price and decide whether or not to pursue a case. They find that the cartel's equilibrium price is decreasing in the fines. LaCasse (1995) and Polo (1997) follow this approach.

The interest for studying the effect of the antitrust policy on the collusive behavior has 
reemerged. Harrington (2004) and Harrington (2005) explore how detection affects cartel pricing when detection and penalties are endogenous. Firms want to raise prices but not suspicions that they are coordinating their behavior. In Harrington (2005), by assuming the probability of detection is sensitive to price changes, he shows that the steady-state price is decreasing in the damage multiple and in the probability of detection. However, he finds a long-run neutrality result with respect to fixed penalties. Harrington (2004) studies the interaction of internal cartel stability and detection avoidance. One important result that he finds is the perverse effect of the antitrust law. The risk of detection and penalties can serve to stabilize a cartel and thereby allow it to set higher prices.

In these papers, the antitrust policy is endogenous to the model and it contrasts with the competition authority defined in this paper. We adopt an antitrust policy that is as simple as possible, because we want to focus our efforts on understanding the network that is formed once the antitrust policy is set.

Nevertheless, in a static setting when no legal errors are present (false conviction), the penalty, assumed costless to impose, should be set as high as possible in order to deter collusive behavior (Beckerian incentives approach). In the present paper, the punishment equals to firms' limited liability as, for example, Besanko and Spulber.

Similar to the present article, for instance, Motta and Polo (2003), Chen and Rey (2007) use a fixed probability of inspection, ${ }^{1}$ but in a leniency program context. Specifically, they study the antitrust enforcement under leniency programs and analyze the incentives to collude when the probability of detection and penalties are both fixed.

On the other hand, Frezal (2006), in a dynamic setting, focuses on the study of the design of optimal audit policy. He concludes that a deterministic and non-stationary policy, where a given industry is controlled every $T$ periods, may be more effective than a stationary one (where an industry is audited with a fixed probability at each period).

The outline of this paper is as follows: Section 2 presents the model of market-sharing agreements and provides general definitions concerning networks. Section 3 characterizes the stable and strongly stable collusive networks in the symmetric context. Section 4 studies the set of pairwise stable and strongly stable networks under different levels of antitrust enforcement. Furthermore, this section analyzes the impact of the antitrust authority over competition. Section 5 discusses where the antitrust policy defined in this paper is in the theory and in the practices of antitrust enforcement. In addition, it also examines some extensions of the current research. The paper concludes in Section 6. All proofs are relegated to the Appendix.

\footnotetext{
${ }^{1}$ Motta and Polo (2003) initially treat the enforcement parameter as exogenous. By doing that, they focus on the game played by firms for a given policy. After that, they analyze the optimal policy under the antitrust authority's constraint.
} 


\section{The Model}

\subsection{Firms}

The model consists of $N$ risk neutral symmetric firms indexed by $i=1,2, \ldots, N$. Each firm is associated to a market (i.e., its home market). Markets are assumed symmetric. We are considering that each firm has incentives to enter into all foreign markets. However, firm $i$ does not enter into foreign market $j$, and vice versa, if a reciprocal market-sharing agreement exists between them. A reciprocal market-sharing agreement is an agreement whereby two firms agree not to enter each other's territory. ${ }^{2}$

Let $g_{i j} \in\{0,1\}$ denote the existence of an agreement between firms $i$ and $j$. Thus, we will say that firm $i$ has signed an agreement with firm $j$ and vice versa, if $g_{i j}=1$.

Let $n_{i}$ be the number of active firms in market $i$ and $m_{i}$ be the number of agreements formed by firm $i$. That is, $n_{i}=N-m_{i}$.

Let $\pi_{j}^{i}(\cdot)$ be the profits of firm $i$ on market $j$. Firm $i$ has two sources of profits. Firm $i$ collects profits on its home market, $\pi_{i}^{i}\left(n_{i}\right)$, and on all foreign market where there does not exist an agreement, $\sum_{j, g_{i j}=0} \pi_{j}^{i}\left(n_{j}\right)$.

The symmetric firm and symmetric market assumptions allow us to write $\pi_{j}^{i}(\cdot)=\pi(\cdot)$. Therefore, total profits of firm $i$ can be written as follows:

$$
\Pi^{i}=\pi\left(n_{i}\right)+\sum_{j, g_{i j}=0} \pi\left(n_{j}\right)
$$

It is assumed that firms have limited liability, i.e., $\Pi^{i} \geq 0$ is the maximum amount that the firm could pay in case a penalty were imposed by an antitrust authority.

\section{Properties of profit functions}

This paper appeals to the same properties for profit functions as Belleflamme and Bloch (2004), henceforth BB. The profit functions satisfy the following properties:

Property 1: Individual profits are decreasing in the number of active firms in the market, $\pi\left(n_{i}-1\right)-\pi\left(n_{i}\right) \geq 0$.

Property 2: Individual profits are convex in the number of active firms in the market, $\pi\left(n_{i}-1\right)-\pi\left(n_{i}\right) \geq \pi\left(n_{i}\right)-\pi\left(n_{i}+1\right)$.

\footnotetext{
${ }^{2}$ It is assumed that these agreements are enforceable.
} 
Property 3: Individual profits are log-convex in the number of active firms in the market, $\frac{\pi\left(n_{i}-1\right)}{\pi\left(n_{i}\right)} \geq \frac{\pi\left(n_{i}\right)}{\pi\left(n_{i}+1\right)}$.

It is important to note that Property 1 is satisfied in the most standard oligopoly models. In spite of the fact that Property 2 and Property 3 are more restrictive than Property 1 , $\mathrm{BB}$ provide sufficient conditions under which these properties hold in a symmetric Cournot oligopoly context. ${ }^{3}$

\subsection{The Antitrust Authority}

We define an antitrust authority (AT) as a pair $\{\alpha, F(\Pi)\}$, where $\alpha \in[0,1)$ is the constant probability that a market-sharing suit is initiated, and $F(\Pi) \geq 0$ represents the monetary penalty that a firm must pay if it is convicted of market-sharing agreements. $F(\Pi)$ is a function that depends on the profits $(\Pi)$ that a fined firm ends up having. In fact, we assume that the penalty will be equal to the total profits that a guilty firm ends up getting. ${ }^{4}$

The technology is such that when the AT inspects, if there exists a market-sharing agreement, then the AT detects it. Moreover, the AT also identifies the two firms involved in the agreement. That is, if a firm is sued for making a market-sharing agreement, the AT is assumed able to detect, without error, whether a market-sharing agreement has occurred. Moreover, if it has occurred, the AT can detect the firms that signed that agreement. In such a case, both firms are penalized and each one must pay $F(\Pi)=\Pi^{i}$.

\section{The antitrust policy and the organization of collusive agreements}

We will show how the organization of collusive conspiracy interacts with the enforcement policy. Particularly, now, we will restrict our attention on the interaction between the structure of illegal agreements and the probability of being detected.

To highlight this issue, let us start by analyzing what is quite standard in the antitrust literature. Assume an AT described by $\{\alpha, F\}$ where $\alpha \in[0,1)$ is the probability of a firm $i$ being inspected and $F \geq 0$ represents the fine imposed by the AT to any guilty firm. Then, we write the expected value of a collusive firm's profits in, for example, a static setting as:

$$
(1-\alpha) \pi(\cdot)+\alpha[\pi(\cdot)-F]
$$

Behind this expression, two important features of enforcement policy are assumed. First, the court system is perfect. That is, when a given collusive firm is reviewed by the AT, the

\footnotetext{
${ }^{3}$ Let $P(Q)$ be the inverse demand function. In a symmetric Cournot oligopoly with homogeneous products, individual profits are decreasing in $n$ if costs are increasing and convex and $E(Q)=\frac{Q P^{\prime \prime}(Q)}{P^{\prime}(Q)}>-1$. In this context, Property 3 is satisfied if costs are linear, $E(Q)>-1$ and $E^{\prime}(Q) \geq 0$.

${ }^{4}$ See Section 5 for a detail discussion.
} 
courts are able to determine without errors that a collusive behavior has occurred. In such situation, the firm is fined with a total penalty $F$. Second, the court system is not able to detect the other members in the collusive agreement. If it were, each firm, when computing its expected collusive benefits, would take into account that when other cartel's members are inspected, it will be also found guilty of collusion.

Therefore, behind the expression (2) it is assumed that the probability of being inspected is equal to the probability of being detected.

However, moving the analysis to scenarios that are more realistic where competition authorities are able to determine the other cartel's members when they inspect, the suitable probability that each firm must consider computing (2) is the probability of being detected. ${ }^{5}$

Given the technology of inspection assumed in the current paper, when a firm $i$ forms a new market-sharing agreement, it will increase its probability of being detected. That is, the probability of firm $i$ being caught by the AT depends not only on whether firm $i$ is inspected but also depends on whether any firm with which firm $i$ has a link is also inspected. ${ }^{6}$ Thus, a firm $i$ will not be detected if $i$ is not inspected and any firm $j$ that has an agreement with $i$ is not inspected. That is,

$$
\operatorname{Pr}(\text { No Detected } i)=\operatorname{Pr}\left(\text { No inspected } i \bigcap_{\substack{j \neq i \\ g_{i j}=1}} \text { No inspected } j\right)
$$

or equivalently, ${ }^{7}$

$$
\operatorname{Pr}(\text { No Detected } i)=(1-\alpha)^{N-n_{i}+1}
$$

Therefore, from a firm's point of view, the probability of not being detected is endogenous and depends on how many agreements firm $i$ has signed, i.e., $m_{i}=N-n_{i}$. Note that, as the number of agreements $m_{i}=N-n_{i}$ increases, $\operatorname{Pr}($ No Detected $i) \rightarrow 0$. On the other hand, as $m_{i}=N-n_{i}$ goes to $0, \operatorname{Pr}($ No Detected $i) \rightarrow(1-\alpha){ }^{8}$

From the AT's point of view, the structure of relationships, described by $m_{i}=N-n_{i}$, generates scale economies on detection since

$$
\operatorname{Pr}(\text { Detected } i)=1-(1-\alpha)^{N-n_{i}+1}>\operatorname{Pr}(\text { Inspected } i)=\alpha
$$

\footnotetext{
${ }^{5}$ See Section 5 for a detail discussion.

${ }^{6}$ We only consider the immediate link.

${ }^{7}$ It is assumed that events "no inspection $i$ " and "no inspection $j$ " are independent each other.

${ }^{8}$ Observe that the $\operatorname{Pr}($ Detected $i)=1-\operatorname{Pr}($ No Detected $i)$ is increasing and concave in the number of agreements signed. That is, as $m_{i}=N-n_{i}$ increases, the probability of being detected increases. However, it increases at a decreasing rate.
} 


\subsection{Incentives to form an agreement}

An essential part of the model is the firm's incentive to form an agreement. Assume that, firm $i$ has formed $m_{i}=N-n_{i}$ agreements, but does not yet form an agreement with a firm $j$, i.e., $g_{i j}=0$. Then, by using expressions (1) and (3), we compute firm $i$ ' expected profits as:

$$
(1-\alpha)^{N-n_{i}+1} \Pi^{i}+\left(1-(1-\alpha)^{N-n_{i}+1}\right)\left[\Pi^{i}-F(\Pi)\right]
$$

where $\Pi^{i}=\pi\left(n_{i}\right)+\pi\left(n_{j}\right)+\sum_{k \neq j, g_{k i}=0} \pi\left(n_{k}\right)$, and $F(\Pi)=\Pi^{i}$.

Now, if firm $i$ decides to form a link with firm $j$, its expected profits will be

$$
(1-\alpha)^{N-n_{i}+2} \Pi^{i}+\left(1-(1-\alpha)^{N-n_{i}+2}\right)\left[\Pi^{i}-F(\Pi)\right]
$$

but now, $\Pi^{i}=\pi\left(n_{i}-1\right)+\sum_{k \neq j, g_{k i}=0} \pi\left(n_{k}\right)$.

By subtracting (4) from (5), we obtain firm $i$ 's incentive to form an agreement with firm $j$ as:

$$
\Delta \Pi=(1-\alpha)^{N-n_{i}+1}\left[\pi\left(n_{i}-1\right)-\pi\left(n_{i}\right)-\pi\left(n_{j}\right)-\alpha\left(\pi\left(n_{i}-1\right)+\sum_{k \neq j, g_{k i}=0} \pi\left(n_{k}\right)\right)\right]
$$

Let $J_{j}^{i}\left(n_{i}, n_{j}, n_{k} ; \alpha\right)$ denote the bracket expression in (6). Then, it can be rewritten as:

$$
\Delta \Pi=(1-\alpha)^{N-n_{i}+1} J_{j}^{i}\left(n_{i}, n_{j}, n_{k} ; \alpha\right)
$$

It is worth noting that when the antitrust authority exists, firm $i$ 's incentive to form a market-sharing agreement with firm $j$ depends not only on characteristics of markets $i$ and $j$ but also on characteristics of market $k$ and on the probability of inspection $\alpha{ }^{9}$

We are interested in the sign of $\Delta \Pi$ because it is what is relevant to decide whether or not one more link is formed. That is, if $\Delta \Pi \geq 0$, firm $i$ has an incentive to form an agreement with $j$.

\footnotetext{
${ }^{9}$ We just consider the case when $m_{i}=N-n_{i} \neq 0$. However, when firm $i$ is isolated, i.e. $m_{i}=N-n_{i}=0$, the firm $i$ 's incentive to form an agreement is slightly different from (6). That is, $\Delta \Pi=\pi(N-1)(1-\alpha)^{2}-$ $\pi(N)-\pi\left(n_{j}\right)-\sum_{k \neq j, g_{k i}=0} \pi\left(n_{k}\right)\left(1-(1-\alpha)^{2}\right)$.
} 
Therefore, when $\alpha \neq 1, \Delta \Pi \geq 0$ only if $J_{j}^{i}\left(n_{i}, n_{j}, n_{k} ; \alpha\right) \geq 0$. Hence, in the following, we will focus only on $J_{j}^{i}\left(n_{i}, n_{j}, n_{k} ; \alpha\right)$.

Thus, forming one more link has several conflicting consequences. From firm $i$ 's point of view, notice that when a new link is formed, firm $i$ agrees not to enter market $j$, hence firm $i$ loses access to foreign market $j$ and it decreases its profits by $-\pi\left(n_{j}\right)$. Given the reciprocal nature of this agreement, firm $j$ does not enter market $i$ either. Therefore, the number of active firms in market $i$ will decrease and it increases its profits by $\pi\left(n_{i}-1\right)-\pi\left(n_{i}\right)$. However, if firm $i$ is detected on this new agreement, and it is inspected with probability $\alpha$, firm $i$ will lose $\pi\left(n_{i}-1\right)+\sum_{k \neq j, g_{k i}=0} \pi\left(n_{k}\right)$

Note that, as $\pi(\cdot)$ is a decreasing function, when $n_{j}$ decreases, it decreases the incentive to lose a more profitable market by forming a link. Then, $J_{j}^{i}$ is increasing in $n_{j}$.

Likewise, $J_{j}^{i}$ is increasing in $n_{k}$. As $n_{k}$ gets smaller, the expected costs of signing an agreement with $j$ become greater. ${ }^{10}$ Hence, it decreases the incentive to form a collusive agreement.

On the other hand, as $\pi(\cdot)$ is a convex function, $J_{j}^{i}$ is decreasing in $n_{i}$. As the number of competitors in its home market decreases, $(1-\alpha) \pi\left(n_{i}-1\right)-\pi\left(n_{i}\right)$ increases.

Concerning the antitrust policy, when the probability of inspection $\alpha$ increases, $J_{j}^{i} d e$ creases, because it increases the expected cost of forming a link.

To sum up, the relationship between firms and the competition authority is the following. Given the antitrust policy $\{\alpha, F(\Pi)\}$, firms compute the incentives to form agreements, and then decide whether to form an agreement or not. Firms form them if they yield positive net profits after expected penalties from signing market-sharing agreements. If an inquiry is opened, and if a firm is convicted of forming a market-sharing agreement, it must pay $F(\Pi)$.

\subsection{Background definitions}

In this part, we provide some definitions that will be useful in describing and analyzing the model.

That is, we are considering firms that enter into bilateral relationships with each other, i.e., market-sharing agreements are bilateral agreements; and the set of them gives rise to a collusive network $g$.

Hence, we introduce some notations and terminology from graph theory to study that collusive network.

${ }^{10}$ The expected cost is $-\left(\alpha \sum_{k \neq j, g_{k i}=0} \pi\left(n_{k}\right)\right)$. 
Networks Let $N=\{1,2, \ldots, N\}, N \geq 3$ denote a finite set of identical firms.

For any $i, j \in N$, the pairwise relationship or link between the two firms is captured by a binary variable $g_{i j} \in\{0,1\}$, where $g_{i j}=1$ means that there exists a link between firms $i$ and $j$. In other words, firms $i$ and $j$ serve a link.

A network $g=\left\{\left(g_{i j}\right)_{i, j \in N}\right\}$ is a description of the pairwise relationship between firms.

Let $g+g_{i j}$ denote the network obtained by adding link $i j$ to an existing network $g$; and denote by $g-g_{i j}$ the network obtained by deleting link $i j$ from an existing network $g$.

Some networks that play a prominent role in our analysis are the following two: the complete network and the empty network.

The complete network, $g^{c}$, is a network in which $g_{i j}=1, \forall i, j \in N$.

In contrast, the empty network, $g^{e}$, is a network in which $g_{i j}=0, \forall i, j \in N, i \neq j$.

Formally, a firm is isolated if $g_{i j}=0, \forall j \neq i$ and $\forall i, j \in N$.

Paths and Components A path in a network $g$ between firms $i$ and $j$ is a sequence of firms $i_{1}, i_{2}, \ldots, i_{n}$ such that $g_{i i_{1}}=g_{i_{1} i_{2}}=g_{i_{2} i_{3}}=\ldots=g_{i_{n} j}=1$. We will say that a network is connected if there exists a path between any pair $i, j \in N$.

A component of a network $g$, is a nonempty subnetwork $g^{\prime} \subset g$, such that: (1) if $i \in g^{\prime}$ and $j \in g^{\prime}$ where $i \neq j$, then there exists a path in $g^{\prime}$ between $i$ and $j$. And, (2) if $i \in g^{\prime}$ and $i, j \in g$ then $i, j \in g^{\prime}$. Thus, a component of a network $g$ is a maximally connected subset of $g$. Note that from this definition, an isolated firm is not considered a component.

Let $m_{i}\left(g^{\prime}\right)$ denote the number of links that firm $i$ has in $g^{\prime}$.

A component $g^{\prime} \subset g$ is complete if $g_{i j}=1$ for all $i, j \in g^{\prime}$. For a complete component $g^{\prime}$, $m_{i}\left(g^{\prime}\right)+1$ denote its size, i.e., it is the number of firms belonging to $g^{\prime}$.

The next figure represents a network with two complete components and an isolated firm.
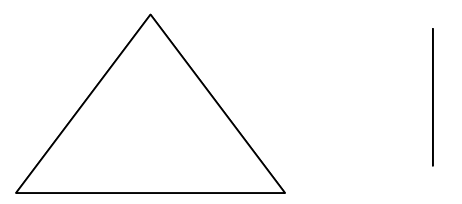

Figure 1: Two complete components of size 3 and 2 and one isolated firm.

Stable collusive networks Our interest is to study which networks are likely to arise. Hence, we need to define a notion of stability. In the present paper, we always use a notion of pairwise stability. 
Pairwise stable networks The following approach was taken by Jackson and Wolinsky (1996). A network $g$ is pairwise stable if and only if: (i) $\forall i, j \in N$ such that $g_{i j}=1$, $\Pi^{i}(g) \geq \Pi^{i}\left(g-g_{i j}\right)$ and $\Pi^{j}(g) \geq \Pi^{j}\left(g-g_{i j}\right)$; and (ii) $\forall i, j \in N$ such that $g_{i j}=0$, if $\Pi^{i}\left(g+g_{i j}\right)>\Pi^{i}(g)$ then $\Pi^{j}\left(g+g_{i j}\right)<\Pi^{j}(g)$.

In terms of our model, a network $g$ is said to be pairwise stable if and only if:

$$
\begin{aligned}
& \text { (i) } \forall i, j \text { s.t. } g_{i j}=1,\left\{\begin{array}{l}
J_{j}^{i}\left(n_{i}+1, n_{j}+1, n_{k} ; \alpha\right) \geq 0 \\
J_{i}^{j}\left(n_{j}+1, n_{i}+1, n_{k} ; \alpha\right) \geq 0
\end{array}\right. \\
& \text { (ii) } \forall i, j \text { s.t. } g_{i j}=0,\left\{\begin{array}{c}
\text { if } J_{j}^{i}\left(n_{i}, n_{j}, n_{k} ; \alpha\right)>0 \\
\text { then } J_{i}^{j}\left(n_{j}, n_{i}, n_{k} ; \alpha\right)<0
\end{array}\right.
\end{aligned}
$$

It is worth noting that the first part of the definition requires that no firm would want to delete a link that it serves. In other words, any firm has the discretion to unilaterally delete the link. This contrasts with the second part of the definition. It means that the consent of both is necessary to form a link. That is, forming a link is a bilateral decision.

The above stability notion is a relatively weak criterion in the sense that it provides broad predictions and the firm's deviations are constrained. A pairwise stability criterion only considers deviations on a single link at a time. ${ }^{11}$ Furthermore, the pairwise stability notion considers only deviations by a pair of players at a time. ${ }^{12}$

Nevertheless, that criterion provides a test to eliminate the unstable networks and it should be seen as a necessary, but not sufficient condition for a network to be stable.

Strongly pairwise stable networks In order to obtain a stronger stability concept we allow deviations by coalitions of firms. We allow firms to delete some or all market-sharing agreements that they have already formed.

We say that a network is pairwise strongly stable if it is immune to deviations by coalitions of two firms.

As BB do, we consider the simultaneous linking game introduced by Myerson (1991). Each firm $i$ chooses the set $s_{i}$ of firms with which it wants to form a link. Thus, $g_{i j}=1$ if and only if $j \in s_{i}$ and $i \in s_{j}$. Let $g\left(s_{1}, s_{2}, \ldots, s_{n}\right)$ denote the network formed when every $i$ chooses $s_{i .}$.

A strategy profile $\left\{s_{1}^{*}, s_{2}^{*}, \ldots, s_{n}^{*}\right\}$ is a pairwise strong Nash equilibrium of the game if and only if it is a Nash equilibrium of the game and there does not exist a pair of firms $i$ and $j$ and strategies $s_{i}$ and $s_{j}$ such that $\Pi^{i}\left(g\left(s_{i}, s_{j}, s_{-i j}^{*}\right)\right) \geq \Pi^{i}\left(g\left(s_{i}^{*}, s_{j}^{*}, s_{-i j}^{*}\right)\right)$ and $\Pi^{j}\left(g\left(s_{i}, s_{j}, \ldots, s_{-i j}^{*}\right)\right) \geq \Pi^{j}\left(g\left(s_{i}^{*}, s_{j}^{*}, \ldots, s_{-i j}^{*}\right)\right)$ with a strict inequality for one of the two

\footnotetext{
${ }^{11}$ On the contrary, for example, it is possible that a firm would not benefit from forming a single link but would benefit from forming several links simultaneously.

${ }^{12}$ It could be that larger groups of player can coordinate their actions in order to all be better off.
} 
firms. A network $g$ is strongly pairwise stable if and only if there exists a pairwise strong Nash equilibrium of the game $\left\{s_{1}^{*}, s_{2}^{*}, \ldots, s_{n}^{*}\right\}$ such that $g=g\left(s_{1}^{*}, s_{2}^{*}, \ldots, s_{n}^{*}\right)$.

It can be proved that any strongly pairwise stable network is pairwise stable. ${ }^{13}$

Thus, the strong stability notion can be thought of as sufficient condition for stability.

\section{Stable collusive networks in the symmetric context}

In this section, we will characterize pairwise stable and strongly pairwise stable networks under the presence of the AT in a symmetric context. Let us recall that the pairwise stability notion might be thought of as a necessary but not sufficient condition for stability, and the strong pairwise stable criterion provides a sufficient requirement for a network to be stable over time. Also, recall that any strong pairwise stable network is pairwise stable.

\subsection{Pairwise stable collusive network}

The following two lemmas provide the necessary conditions on pairwise stability.

Lemma 1 Under Property 1, if network $g$ is stable, then $\forall i, j \in N$ such that $g_{i j}=1$, $n_{i}(g)=n_{j}(g)$.

In the following, we simply use $n_{i}(g)=n_{i}$. From the Lemma we conclude that two firms are connected by a market-sharing agreement in a stable network if they have the same number of competitors on their home markets. If not, the link is not served. That is, if $n_{i} \neq n_{j}$, the firm in the less profitable market (with larger number of competitors in its home market) does not have incentive to lose access to a more profitable one (with a smaller number of competitors) by signing a market-sharing agreement.

A straightforward implication of this is that an isolated firm, with $N$ competitors in its home market, refuses to form a link with any firm $j$ such that $n_{j}<N$. That is, if $n_{j}<N$, under Property 1 , then $\pi(N-1) \leq \pi\left(n_{j}\right)$. Therefore, from $J_{j}^{i}$, s expression, it will be also true that

$$
(1-\alpha) \pi(N-1)<\pi(N)+\pi\left(n_{j}\right)+\alpha\left[\sum_{k: g_{i k}=0} \pi\left(n_{k}\right)\right]
$$

Lemma 2 Under Property 1 and 3, if network $g$ is stable, then any component $g^{\prime}$ of $g$ is complete. Moreover, these complete components have different sizes.

Then, by Lemma 2, a pairwise stable network can be decomposed into complete alliances of different sizes. Then, if a set of firms is linked, all of them must be linked by a market-

\footnotetext{
${ }^{13}$ See Belleflamme and Bloch (2004).
} 
sharing agreement among themselves, i.e., complete components. ${ }^{14}$ Moreover, if a pairwise stable network has more than one component, they have different sizes. As BB already establish, the intuition underlying this result is due to free riding. If a firm $i$ has signed more agreements than other firms, market $i$ is a very profitable one. Therefore, the other firms will not want form a link with firm $i$ because they do not want to lose access to a profitable market. In other words, the other firms free ride on the agreements signed by firm $i$. By extending this argument, we say that firms in smaller alliances (with larger number of competitors in their home markets) free ride on the agreements signed by firms in larger ones (with smaller number of competitors) as any firm belonging to a small alliance has no incentive to form an agreement with a firm that belongs to a large one.

Now, let us observe that Lemma 1 and Lemma 2 are stated only by using Property 1 and 3. Hence, in the absence or under the presence of the AT, both lemmas are always true. Additionally, let us note that Lemma 1 and 2 talk about linked firms and how they are linked. Then, in that context, two questions become relevant. Does the AT have any impact on the size of the linked firms' alliances? Does the AT have any impact on the set of firms that remain without links? The answer to them is interconnected. In our setting, the competition authority affects the net expected profits from entering into a market-sharing agreement, and in turn impacts on the decision whether or not a link is formed. Thus, $g_{i j}=1$ only if

$$
(1-\alpha) \pi(n-1) \geq 2 \pi(n)+\alpha \sum_{k \neq j, g h k=0} \pi\left(n_{k}\right), \text { for } k \neq h=i, j
$$

Let us see the impact of the AT on the decision to participate in a collusive agreement.

In the absence of the AT, i.e., $\alpha=0,{ }^{15}$ the above inequality becomes $\pi(n-1)>2 \pi(n)$. Therefore, by log-convexity, it is possible to guarantee the existence of a number $n^{*}=N-m^{*}$ such that $\pi\left(n^{*}-1\right) \geq 2 \pi\left(n^{*}\right)$. Thus, $m^{*}=N-n^{*}$ is interpreted as the minimal number of agreements that a firm already has to have in order to form an additional one. In the absence of a competition authority, there exists a lower bound on the size of collusive alliances, which does not depend on $g$. Moreover, when $m^{*}=1$, the number of isolated firms is at most 1 .

\footnotetext{
${ }^{14}$ In other words, $J_{j}^{i}>0$ is increasing in the number of agreements already signed by firm $i$. To see this, let us consider firms $i, j$ and $l$. By now, let us focus only on firm $i$ (the same explanation applies to firms $j$ and $l$ ). When firms $i, j$ and $l$ are linked in some way, and $J_{j}^{i}>0$, then it will be also true that $J_{l}^{i}>0$. That is, $J_{j}^{i}>0$ means that $(1-\alpha) \pi\left(n_{i}-1\right)-\pi\left(n_{i}\right)>\pi\left(n_{j}\right)+\alpha\left(\pi\left(n_{l}\right)+\sum_{k \neq j, k \neq l, g_{k i}=0} \pi\left(n_{k}\right)\right)$. Therefore, under the profit functions' properties, it will be true that $J_{l}^{i}>0$. That is, $(1-\alpha) \pi\left(n_{i}-2\right)-\pi\left(n_{i}-1\right)>$ $\pi\left(n_{l}\right)+\alpha \sum_{k \neq j, k \neq l, g_{k i}=0} \pi\left(n_{k}\right)$.

${ }^{15}$ It is the Belleflamme and Bloch's setting.
} 
In contrast, under the presence of the AT, i.e., $\alpha \neq 0$, we are not able to reach an unique lower bound. From (7) we can see that the maximal number of competitors that assures that the condition holds depends on each $\alpha$ and on each network $g$. Moreover, we will see that if in a stable network the alliance of minimum size is equal to 1 , it does not impose any restriction on the set of isolated firm. The consequences of that over competition will be discussed further in Section 4.

Consider the following network $g$ that can be decomposed into distinct complete components, $g_{1}, \ldots, g_{L}$, of different sizes, i.e., $m\left(g_{l}\right) \neq m\left(g_{l^{\prime}}\right), \forall l, l^{\prime}$.

Let us define $m\left(g_{h}^{*}\right):=\min \left\{m\left(g_{1}\right), \ldots, m\left(g_{L}\right)\right\}$. That is, $g_{h}^{*}$ is the smallest component of network $g$, whose size is $m\left(g_{h}^{*}\right)+1$.

The next lemma shows a sufficient condition on pairwise stability in our collusive context.

Lemma 3 Given a network $g$ that can be decomposed into a set of isolated firms and different complete components, $g_{1}, \ldots, g_{L}$, of different sizes $m\left(g_{l}\right) \neq m\left(g_{l^{\prime}}\right), \forall l, l^{\prime}$, if firm $i \in g_{h}^{*}$ does not have incentives to cut a link with a firm inside its alliance, then any $j \in g_{l}$ will not have incentives to cut a link with a player inside its component for all $g_{l} \neq g_{h}^{*}$.

The lemma provides a condition to check whether a firm has incentives to renege on one agreement. Then, given a network $g$, it is sufficient to verify what happen inside the smallest component. The intuition is as follows. A firm that belongs to the smallest component has two disadvantages: (i) it has a larger number of competitors in its home market than any firm that belongs to a greater alliance, and (ii) if the antitrust authority detects its agreements, it loses profits on markets where it does not collude, ${ }^{16}$ and they are larger than the same kind of profits of a firm that belongs to a larger cartel. ${ }^{17}$ Therefore, if any firm $i \in g_{h}^{*}$ has no incentive to renege on one agreement, no other linked firm will have it.

By combining the previous Lemmas, we state the following.

Proposition 1 A network $g$ is stable if and only if it can be decomposed into a set of isolated firms and distinct complete components, $g_{1}, \ldots, g_{L}$ of different sizes $m\left(g_{l}\right) \neq m\left(g_{l^{\prime}}\right), \forall l, l^{\prime}$ such that neither an isolated firm has an incentive to form a link with another isolated one nor a firm $i$ that belongs to the smallest component has an incentive to cut a link with a firm inside it.

The above Proposition provides the characterization of the pairwise stable networks in the symmetric context when the AT exists. Note that the Proposition holds for all $m\left(g_{h}^{*}\right) \geq 1$.

\footnotetext{
${ }^{16}$ That is, $\sum_{k, g_{k i}=0} \pi\left(n_{k}\right)$.

${ }^{17}$ Assume for simplicity that there are only two complete alliances, and $i \in g_{l}$ and $j \in g_{l^{\prime}}$, where $m\left(g_{l}\right)<$ $m\left(g_{l^{\prime}}\right)$. Then, $\sum_{k, g_{k i}=0} \pi\left(n_{k}\right)=\left[m\left(g_{l^{\prime}}\right)+1\right] \pi\left(n_{j}\right)>\sum_{k, g_{k j}=0} \pi\left(n_{k}\right)=\left[m\left(g_{l}\right)+1\right] \pi\left(n_{i}\right)$.
} 
From that characterization, we can predict that collusive alliances are complete, and they have different sizes. However, we know that from the BB's setting. Hence, the AT does not change that prediction.

Nevertheless, the AT imposes a change in the minimal size of the components and it does not restrict the set of isolated firms. In the absence of the AT, i.e., the BB's setting, a network is stable if its alliances are large enough. That is, the complete components have to reach a minimal size, i.e., $m^{*}$. Moreover, if $m^{*}=1$, there is, at most, one isolated firm.

However, under the presence of the AT, that threshold, i.e., $m\left(g_{h}^{*}\right)$, depends on each $g$ and on each $\alpha$.

By rewriting (7), we obtain the following:

$$
\frac{\pi(n-1)}{\pi(n)} \geq \frac{2}{(1-\alpha)}+\frac{\alpha \sum_{k: g_{h k}=0} \pi\left(n_{k}\right)}{(1-\alpha) \pi(n)} \geq 2, \text { for } k \neq h=i, j
$$

Therefore, and in spite of the fact that $m\left(g_{h}^{*}\right)$ depends on particular conditions, it is easy to see that $m\left(g_{h}^{*}\right) \geq m^{*}$. Nevertheless, in Section 4 , we will show that this is not necessarily a perverse effect of the AT because $m\left(g_{h}^{*}\right) \geq 1$ does not put any restriction on the set of isolated firm.

\subsection{Pairwise strongly stable collusive network}

We refine the set of stable networks by using the strong stability condition. Let us recall that the difference between stability and strong stability arises from the firms' ability to delete more than one link at once.

Then, we now allow firms to delete a subset of links already formed and we will study when a firm has no incentive to renege on its agreements. This point is very important in our context because a network composed by large alliances will be hard to sustain.

Proposition 2 A network $g$ is pairwise strongly stable if and only if it is pairwise stable and no firm prefers to cut all its agreements at once, that is

$$
(1-\alpha)^{N-n+1} \pi(n) \geq \pi(N)+(N-n) \pi(n+1)+\sum_{k, g i=0} \pi\left(n_{k}\right)\left(1-(1-\alpha)^{N-n+1}\right), \forall n=N-m+1
$$

Accordingly, the fact that a firm has no incentives to renege on all its links at once is a sufficient condition for strong stability. To see this, assume that a firm reneges on one of its agreements. Then, it gains access to a market whose profits are at least equal to the profit it makes on its home market after cutting a link. Therefore, if a firm has incentive to cut one agreement, the most profitable deviation for it is to renege on all its agreements at once. 
Thus, in a strongly stable network, component sizes satisfy a more demanding condition.

It is worth remarking that a strongly stable network may fail to exist. Notwithstanding, one important advantage of the strong criterion is to provide a more accurate prediction of which network structures will prevail

\subsection{Examples}

Example 1 Pairwise Stable Network for $\alpha=0$ and $\alpha \neq 0$. Cournot competition with exponential inverse demand function $P(Q)=e^{-Q}$

When inverse demand function is $P(Q)=e^{-Q}$, we can compute the equilibrium profits as $\pi(n)=e^{-n}$.

In the absence of the AT, i.e., $\alpha=0$, the pairwise stability condition (8) becomes

$$
\frac{\pi(n-1)}{\pi(n)}=e \geq 2, \forall n
$$

Hence, any two firms have incentives to form a link. Therefore, $m^{*}=1$ and any network with complete components of different sizes with at most one isolated firm is pairwise stable.

In contrast, when AT exists, i.e., $\alpha \neq 0$ that is no longer true. Assume, for example, $N=7$ and $\alpha=0.025$. In such a context, the following is one network configuration that belongs to the set of the pairwise stable networks:

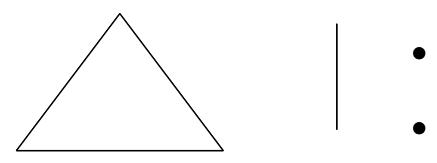

Figure 2: Stable network, $N=7$ and $\alpha=0.025$.

Let us observe that in this case $m\left(g_{h}^{*}\right)=1$, and the number of isolated firms in that stable network is greater than 1 . This result is in sharp contrast to the prediction established in the absence of the AT.

We can easily check the sufficient conditions for pairwise stability: (i) no firm in the smallest component wants to cut a link that it serves because it is profitable to maintain it. That is, (8) holds (the Appendix contains all calculations); (ii) for any isolated firm, it is true that $\frac{\pi(6)}{\pi(7)}<\frac{2}{(1-\alpha)}+\frac{\alpha(3 \pi(5)+2 \pi(6))}{(1-\alpha) \pi(7)}$.

Example 2 Pairwise Stable Network and Strongly Stable Network for $\alpha=0$ and $\alpha \neq 0$. Cournot competition with exponential inverse demand function $P(Q)=e^{-Q}$

As stated above, in this competition context, $\pi(n)=e^{-n}$.

Now, assume $N=5$. The following table depicts the set of pairwise stable (ps) and pairwise strongly stable (pss) networks for $\alpha=0$ and for $\alpha=0.04$. First of all, it is useful 
to clarify some notations there. In the table, the complete network is represented by $\{5\}$ and, for example, $\{3,1,1\}$ denotes a network decomposed into two isolated firms and one complete component of size three.

Table 1

\begin{tabular}{crc}
\hline \multicolumn{1}{c}{$\alpha$} & Set of ps networks & Set of pss networks \\
\hline$\alpha=0$ & $\{3,2\},\{4,1\},\{5\}$ & $\{3,2\}$ \\
$\alpha=0.04$ & $\{3,1,1\},\{4,1\},\{5\}$ & It fails to exist
\end{tabular}

When $\alpha=0$, any two firm have an incentive to form a market-sharing agreement, as $\frac{\pi(n-1)}{\pi(n)}=e \geq 2, \forall n$. In other words, for $\alpha=0, m^{*}=1$.

By applying the strong stability condition, we obtain that only components of size 3 and 2 are strongly stable.

Let us note, from Table 1, that the strong criterion selects a subset of stable networks, and it allows us to improve our prediction about which networks prevail over time.

Now, let us observe that, for $\alpha=0.04, m\left(g_{l}^{*}\right)=2>m^{*}=1$. In spite of this fact, it is easy to see that the network $\{3,1,1\}$ entails more competition than $\{3,2\}$.

Additionally, this example illustrates that, in some circumstances, the strongly stable network fails to exist, and every network is defeated by some other network which only leads to cycles.

\section{The Antitrust Authority and the set of stable collusive net- works}

In our setting, the presence of the antitrust authority $\{\alpha, F(\Pi)\}$ introduces a negative externality to each formed link, and as a result, the expected gain of being a part of a collusive agreement may not be positive. ${ }^{18}$ That is, the expected sanction imposed by the AT affects the incentive participation constraint of each potential alliance's member, and in turn changes the set of possible network structures that can arise.

Given the network characterization of the previous section, we now analyze which kind of stable networks can be sustained at different levels of the antitrust enforcement.

\subsection{The set of pairwise stable networks}

First of all, a complete network is always pairwise stable for sufficiently low $\alpha$ 's. Let us define $\alpha^{c}:=1-\frac{2 \pi(2)}{\pi(1)}$.

$$
{ }^{18} \mathrm{It} \text { is, } J_{j}^{i}:=\pi\left(n_{i}-1\right)-\pi\left(n_{i}\right)-\pi\left(n_{j}\right)-\alpha\left(\pi\left(n_{i}-1\right)+\sum_{k \neq j, g_{k i}=0} \pi\left(n_{k}\right)\right), \forall i, j \text {. }
$$


Proposition 3 The complete network $g^{c}$ is pairwise stable if and only if $\alpha \leq \alpha^{c}$.

Being a part of a collusive agreement entails positive benefits. To serve a link increases the profits of firms that participate in it (i.e., $\pi(n)$ is decreasing in $n$ ). Therefore, the complete network will be always pairwise stable as long as its costs (i.e., the expected sanction) are sufficiently low.

Second, the empty network arises as pairwise stable for sufficiently high $\alpha$ 's. Let us define $\alpha^{e}(N):=1-\left[\frac{N \pi(N)}{[\pi(N-1)+(N-2) \pi(N)]}\right]^{\frac{1}{2}}$, for $\forall N \in[3, \infty)$.

Proposition 4 For $\forall N \in[3, \infty)$, the empty network $g^{e}$ is pairwise stable if and only if $\alpha>\alpha^{e}(N)$.

For an isolated firm, $\alpha^{e}(N)$ is the threshold from which it has no incentive to participate in an agreement when all other firms also remain isolated. When $\alpha>\alpha^{e}(N)$, the expected costs to form a link are so high, relative to its benefits, that no two firms will sign an agreement.

Moreover, observe that $\alpha^{e}(N)$ is strictly decreasing in $N$. That is, as $N$ increases, the "loot" becomes less "attractive" (i.e., $\pi(N)$ is decreasing in $N$ ), and therefore the threshold will get smaller.

By straightforward computations, we can see that $\alpha^{e}(N)<\alpha^{c}$. Consequently, from the above Propositions, we claim the following:

Claim 1 For $\alpha \in\left(\alpha^{e}(N), \alpha^{c}\right], g^{e}$ and $g^{c}$ belong to the set of pairwise stable networks.

From Proposition 3 and 4 and Claim 1, we can state that pairwise stable networks always exist. That is, first, for $\alpha \leq \alpha^{c}$, the complete network belongs to the set of stable networks. Second, for $\alpha>\alpha^{e}(N)$, the empty network will be stable. And given that $\alpha^{e}(N)<\alpha^{c}$, then $g^{e}$ and $g^{c}$ arise as pairwise stable configurations.

Third, let us recall that $J_{j}^{i}$ is an increasing function in $n_{k}$ and in turn implies that free riding on the market-sharing agreements made by the other firms is no longer "so free". In other words, $\alpha \neq 0$ means that there exists a positive probability of being caught in a market-sharing agreement. Consequently, there exists a positive probability of losing profits not only in the market where the agreement is signed but also in markets in which the firm is active, i.e. in markets where the firm does not collude.

For firms in smaller alliances the cost of forming a link becomes significant, relative to their benefits. That is, a firm $i$ inside a small alliance does not have much to gain and has a lot to lose when one more link is made: (i) it gains $(1-\alpha) \pi\left(n_{i}-1\right)-\pi\left(n_{i}\right)$ that 
gets smaller as the alliance is smaller because the number of active firms is greater in small components; and (ii) it loses not only the access to profits on foreign market $j, \pi\left(n_{j}\right)$, but it also loses, in expected terms, $\alpha \sum_{k: g_{i k}=0} \pi\left(n_{k}\right)$.

Therefore, firms in smaller components are more sensitive to the antitrust enforcement.

The intuition provided above is summarized in the next Proposition.

Before introducing it, let us define

$$
\alpha^{*}\left(n_{i}\right):=\frac{\pi\left(n_{i}-1\right)-2 \pi\left(n_{i}\right)}{\pi\left(n_{i}-1\right)+\sum_{k \neq j, g i=0} \pi\left(n_{k}\right)}
$$

Proposition 5 If $n_{1}>n_{2}$, then $\alpha^{*}\left(n_{1}\right)<\alpha^{*}\left(n_{2}\right)$.

That is, at $\alpha^{*}\left(n_{i}\right)$ a firm $i$, with $n_{i}$ competitors in its home market, is indifferent to form a link or not (i.e., $J_{j}^{i}=0$ ). Therefore, when $\alpha>\alpha^{*}\left(n_{i}\right)$, then $J_{j}^{i}<0$, and firms $i$ and $j$ do not sign a collusive agreement.

From the Proposition follows that the threshold is smaller for firms in smaller alliances (with larger number of competitors in their home markets). Then, as $\alpha$ becomes greater, the AT firstly tears down small alliances, i.e., the smaller components are more sensitive to the antitrust policy. In the limit, firms must decide to form a very large alliance (complete network) or no alliance at all (empty network).

Proposition 6 For $\alpha=\alpha^{c}$, the only pairwise stable networks are $g^{e}$ and $g^{c}$.

Then, by setting $\alpha>\alpha^{c}$, the AT completely deters the formation of collusive agreements.

\subsection{The set of pairwise strongly stable networks}

Now, we turn our attention to strongly stable notion and we answer which kinds of networks arise as the AT changes its enforcement level. From the previous section, we know that there will be some pairwise stable networks that will not be stable against changes in the agreements made by firms. By applying (9), we assert the following:

Proposition 7 As $\alpha$ becomes greater, firms in large components have more incentives to delete all links at once.

That is, as $\alpha$ increases, the strongly stable condition is harder to sustain in larger components. In other words, faced with increasing $\alpha$, a firm has to consider whether to maintain or to destroy its agreements. Therefore, the firm balances the pros and the cons of any decision. Namely, if a firm maintains its agreements, its benefits are $(1-\alpha)^{N-n+1}\left[\pi(n)+\sum_{k, g i=0} \pi\left(n_{k}\right)\right]$. 
Let us note that these benefits decrease as the probability of inspection $(\alpha)$ increases, and the fall in the expected benefits is higher as $m=N-n$ is higher.

Instead, if the firm decides to destroy all its agreements, it is not only not penalized now by the AT, but also it will gain access to markets where it was colluding before. In such a situation, it will make profits on all these new foreign markets, i.e., $(N-n) \pi(n+1)$. Let us observe that these markets are more profitable as the number of competitors on them is smaller, i.e., as $m=N-n$ is larger.

Therefore, firms belonging to larger alliances have more incentives to cut all its agreements at once as the AT increases the cost of forming links.

Now, let us consider the empty network under the strongly stable notion.

It is worth noting that if $g^{e}$ is pairwise stable, it is also strongly pairwise stable, as the condition (9) is always satisfied for firms that remaining alone. That is, in an empty network, firms do not have any link, so the condition of not having incentives to renege on all agreements at once, is redundant for any $i \in g^{e}$. Hence, we claims that

Claim $2 \forall \alpha>\alpha_{e}(N)$ the empty network is always strongly pairwise stable.

Accordingly, if for some $\alpha>\alpha_{e}(N)$ all alliances have been torn down by the antitrust policy, the only network configuration that exists is the empty one.

\subsection{Examples}

The following examples illustrate the changes that the AT imposes in the set of pairwise stable networks. (The Appendix contains all calculations.)

Example 3 Pairwise stable (ps) networks. Cournot competition with exponential inverse demand function $P(Q)=e^{-Q}$

Let us recall that in this context $\pi(n)=e^{-n}$.

Assume that $N=5$. The following table depicts the set of pairwise stable networks for different values of the antitrust policy.

Table 2

\begin{tabular}{lr}
\hline \multicolumn{1}{c}{$\alpha$} & Set of ps networks \\
$\alpha \in[0 ; 0.015)$ & $\{3,2\},\{4,1\},\{5\}$ \\
$\alpha \in[0.015 ; 0.04)$ & $\{3,1,1\},\{4,1\},\{5\}$ \\
$\alpha \in[0.04 ; 0.065)$ & $\{2,1,1,1\},\{3,1,1\},\{4,1\},\{5\}$ \\
$\alpha \in[0.065 ; 0.21)$ & $\{1,1,1,1,1\},\{3,1,1\},\{4,1\},\{5\}$ \\
$\alpha \in[0.21 ; 0.25)$ & $\{1,1,1,1,1\},\{4,1\},\{5\}$ \\
$\alpha \in[0.25 ; 0.26)$ & $\{1,1,1,1,1\},\{5\}$ \\
$\alpha>0.26$ & $\{1,1,1,1,1\}$ \\
\hline
\end{tabular}


Thus, when $\alpha$ is sufficiently low (i.e., $\alpha<0.015$ ) the presence of the AT does not change the set of pairwise stable networks. However, when the antitrust enforcement is sufficiently high (i.e., $\alpha>0.26$ ) the only pairwise stable network is the empty one, and hence all firms are active in all markets.

Consider now values for $\alpha$ 's between these two extreme cases. Although different configurations arise, the main features to be highlighted are the following two. First, when $\alpha$ increases, more structures that are competitive can be sustained through bilateral agreements. In particular, when $\alpha$ becomes greater, the smaller components are more sensitive to the antitrust policy. For example, when $\alpha \in[0.015 ; 0.04)$ the network structure $\{3,2\}$ is no longer stable because firms in smaller components have incentives to cut their agreements and the network $\{3,1,1\}$ becomes stable. Likewise, it is noteworthy that graphs like $\{3,1,1\}$ or $\{2,1,1,1\}$ are not pairwise stable when $\alpha=0$, i.e., BB's setting. Second, as $\alpha$ increases the set of stable network configurations becomes more polarized. That is, in our analytical example, when $\alpha \in(0.25 ; 0.26)$ the empty or complete networks are the only possible stable network configurations. This can be understood because the AT imposes costs of forming links and it reduces the profitability of each one. Hence, firms decide either to form more and more links, i.e. reduce the number of competitors in their home markets, in order to balance their benefits with their cost, or not forming a link at all and by doing that they avoid the costs levied by the AT.

Now, the next example illustrates both the special features of the strong criterion and the impact of the AT on the set of strongly stable networks.

Example 4 Pairwise strongly stable (pss) networks. Cournot competition for exponential inverse demand function: $P(Q)=e^{-Q}$

As in the last example, assume that $N=5$. Given that a pairwise strongly stable network is always pairwise stable, it suffices to check condition (9) for all network structures in Table 2 at different levels of the antitrust policy.

Table 3

\begin{tabular}{lrr}
\hline \multicolumn{1}{c}{$\alpha$} & Set of ps networks & Set of pss networks \\
$\alpha \in[0 ; 0.015)$ & $\{3,2\},\{4,1\},\{5\}$ & $\{3,2\}$ \\
$\alpha \in[0.015 ; 0.04)$ & $\{3,1,1\},\{4,1\},\{5\}$ & it fails to exist \\
$\alpha \in[0.04 ; 0.065)$ & $\{2,1,1,1\},\{3,1,1\},\{4,1\},\{5\}$ & $\{2,1,1,1\}$ \\
$\alpha \in[0.065 ; 0.21)$ & $\{1,1,1,1,1\},\{3,1,1\},\{4,1\},\{5\}$ & $\{1,1,1,1,1\}$ \\
$\alpha \in[0.21 ; 0.25)$ & $\{1,1,1,1,1\},\{4,1\},\{5\}$ & $\{1,1,1,1,1\}$ \\
$\alpha \in[0.25 ; 0.26)$ & $\{1,1,1,1,1\},\{5\}$ & $\{1,1,1,1,1\}$ \\
$\alpha>0.26$ & $\{1,1,1,1,1\}$ & $\{1,1,1,1,1\}$ \\
\hline
\end{tabular}


First, the example clarifies that the possible set of stable networks is reduced by using the strongly stable criterion. However, the strongly stable network might fail to exist and this is what happens for $\alpha \in[0.015 ; 0.04)$.

Second, the incentive to free ride and delete all links is higher in larger alliances. That is, when a firm that belongs to a large alliance cuts all its agreements at once, it will recover access to more profitable markets than a firm belonging to a small component. In the example, the complete network $\{5\}$ and the stable network $\{4,1\}$ do not pass the strongly stable condition. By extending this argument, the empty network is the only strongly stable network for $\alpha>0.065$.

Therefore, antitrust policy is on the side of competition as long as it gives firms in large alliances more incentives to renege on their agreements at once.

\subsection{The AT and its effects on competition}

From the previous analysis, we conclude that, as $\alpha$ increases the smaller alliances are first in being destroyed by the antitrust policy. In turn, the set of isolated firms expands.

Moreover, as $\alpha$ becomes larger, $m\left(g_{h}^{*}\right)$ also increases. However, from Proposition 7 , we know that large alliances are harder to sustain.

Therefore, as $\alpha$ increases, the empty network, $g^{e}$, tends to emerge as the only pairwise strongly stable network. Let us recall that in an empty network, all firms are active in all markets. Then, we infer that the antitrust policy is a pro-competitive one.

As it is well known, in Cournot oligopolies with homogeneous goods, the social surplus $(V)$ is increasing in the number of active firms on the market.

From Proposition 6, when $\alpha>\alpha^{c}$, the $g^{e}$ is the only network that prevails over time. Therefore, in such a case, $V$ would be the maximum.

Although $\alpha>\alpha^{c}$ may be the "advice" to give to the AT, it may not be the optimal antitrust policy, because the necessary costs to attain that enforcement level may outweigh its positive impact on the social surplus. That is, in order to know whether the AT has a net positive effect on social welfare, we must also consider the cost of enforcement.

Thus, the net social welfare, $W$, depends on the network structure $g$ (which depends, at last, on the particular level of $\alpha$ ), as well as, on the cost of initiating a market-sharing agreement suit against a firm $(C)$.

Hence, if the AT were concerned about the optimal antitrust policy, then it would have to choose $\alpha$ such that maximizes

$$
W(g(\alpha), C)=V(g(\alpha))-\alpha C
$$

Unfortunately, in our network context, $g(\alpha)$ is not unique for each $\alpha$. Moreover, a particular network $g$ can emerge as pairwise stable for different levels of $\alpha$. Therefore the optimal 
antitrust policy is difficult to evaluate due to the multiplicity on network configurations for each level of antitrust enforcement.

\section{The AT and collusive networks: a discussion}

The collusive network in market-sharing agreements interacts with the antitrust policy defined by $\{\alpha, F(\Pi)\}$.

As we have seen, in the network context, an agreement, i.e., a link, creates both positive and negative externalities. As the number of competitors in the home market is reduced by a market-sharing agreement, the "booty" of collusive firms increases $(\pi(n)$ is a decreasing function in $n$ ).

In contrast, each link entails negative effects imposed by the AT. One more link increases the probability of being discovered, which is higher than the probability of being inspected $(\alpha)$. Furthermore, the fine imposed by AT depends on the links held by each firm. That is, it is equal to the total profit that each guilty firm $i$ ends up having, and it depends on the $n_{i}$ and $n_{k}$ (see expression (6)). Thus, the penalty ultimately depends on the network structure as a whole.

Our setting is a simpler one, because the aim is focused on the study of formed collusive networks once the antitrust policy is set. At this point, at least two different issues emerge in the discussion.

One of them is where antitrust policy defined in this article $\{\alpha, F(\Pi)\}$ is in the theory and in the practices of the antitrust enforcement.

The second issue is related to the optimal antitrust enforcement. We will briefly discuss, under our network context, whether and how we can move the analysis to consider other enforcement policies in searching of the optimal ones.

\subsection{Theory and practices of the antitrust enforcement}

The struggle against collusive agreements has two elementary tools: (i) the penalty that is imposed to offenders, and (ii) the probability of inspection. Both them are instruments that antitrust authorities use to deter collusion.

\section{Modeling the fines}

From the theoretical perspective. In the economic literature of optimal enforcement, fines are usually assumed as socially costless. Therefore, when the AT seeks to deter collusion, the fines should be set at the maximum level in order to minimize the inspection cost. ${ }^{19}$ An implication of this is that the fines need not to be related to the illegal profits or to the harm

\footnotetext{
${ }^{19}$ This holds when firms are risk-neutral.
} 
that the offenders caused. They only need to be as high as it is possible in order to deter collusion. This implication holds as long as there are not legal errors in the detection process (false convictions), or as long as the fines do not imply bankruptcy to convicted firms.

In the theoretical literature of antitrust policy, some articles set the fine as high as possible. For example, Besanko and Spulber (1989), by assuming a risk neutral cartel, make the fine equal to the firm's limited liability. However, other articles, avoiding any problem, assume the penalties as exogenous parameters and set by the law. ${ }^{20}$

Additionally, other papers consider different regimes of punishment. For example, in Harrington (2004 and 2005), the penalty for a guilty firm is equal to the sum of the firm's damages (i.e., any penalty that is sensitive to the prices charged) and a fixed fine (i.e., fixed with respect to the endogenous variables). Additionally, he assumes the penalty is sufficiently bounded from above in order to avoid the firm's bankruptcy.

Likewise, Souam (2001) studies the optimality between two regimes of penalty that are often used in practice. One of them involves a fine based on revenues and the other one is related to the damage caused to consumers by illegal practices.

From the practical perspective. The theoretical perspective sometimes contrasts with what we find in the actual antitrust policies. For example, both in the EU and in the US, the current laws (i) set a ceiling for the maximum fine, and (ii) try to relate the penalty to the cartel's consequences. The underlying reasons behind these two features are the concern about (i) the firms' ability to pay, and (ii) the presence of legal errors.

That is, if the fines are too high, they may risk the firm's ability to continue competing in the future. This is the reason for which antitrust authorities establish a maximum on fines.

On the other hand, legal errors may deter some socially desirable behavior, like some forms of legal cooperation between firms, which may be misjudged as collusive. In this case, the fine must be related to the harm caused or the gains produced by the cartel's members.

Thus, for example, in European laws, according to Art. 23 and 24 of Regulation $\mathrm{N}^{\circ} 1 / 2003^{21}$ the penalty is a percentage of the collusive firm's turnover. Moreover, Art. 23(3) establishes that "in fixing the amount of the fine, regard shall be had both to the gravity and to the duration of the infringement".

Since, in the present article, we assume that the competition authority does not commit legal errors and the framework is a static one (i.e. we do not care about bankruptcy), then it seems reasonable to set the fine equal to the limited liability of firms, which in our model is equal to the firm's total profits.

\footnotetext{
${ }^{20}$ See, among others, Harrington (2003), Frezal (2006), Chen and Rey (2007) and Motta and Polo (2003).

${ }^{21}$ Council Regulation (EC) $\mathrm{N}^{o} 1 / 2003$, on implementation of the rules on competition laid down in Articles 81 and 82 of the Treaty, articles 23-26.
} 


\section{Modeling the inspection process}

From the theoretical perspective. In modeling the inspection process, most papers assume that antitrust authorities have constant and exogenous budgets that allow them to inspect a fix number of firms. However, competition authorities sometimes have endogenous audit strategies, which determine when a particular firm is inspected.

Thus, for example, in a static setting, the probability of being caught has been studied as an increasing function in the firm's markup over its marginal cost, ${ }^{22}$ or a decreasing function in the observed market quantity. ${ }^{23}$ In a dynamic setting, the probability of being discovered is allowed to depend not only on the current price but also on the previous period's price. ${ }^{24}$

Here, it is worth mentioning that Kühn (2001) offers a detailed discussion about the problems in detecting cartels, beyond the lack of information on cost. He remarks that the information on actual prices or quantities may be unavailable. Moreover, even in the ideal case when the data is acquirable, they may be too sensitive to functional form specifications.

In contrast, other articles consider the probability of inspection as a fixed parameter. For example, Chen and Rey (2007) and Motta and Polo (2003) study the optimal enforcement policy in a leniency program context, and they assume the probability of being investigated as exogenously fixed. ${ }^{25}$

From the practical perspective. A constant and exogenous probability of inspection can be interpreted as a surprise inspection policy, that although it may be effective, ${ }^{26}$ it does not exist in the current practices.

In the EU, for example, there is always initial evidence that motivates the European Commission to investigate. Moreover, in fact, it is quite often provided by cartel members in the leniency programs, internal whistle-blowers and complainants, such as customers or competitors of the alleged cartel.

Moreover, in Europe, the legal basis for inspection ${ }^{27}$ specifies that they are not to be random. According to Art.20(4) of Regulation $\mathrm{N}^{o} 1 / 2003$ the decision to inspect must specify "the subject matter and purpose of the inspection, appoint the date on which (the inspection) is to begin...".

In light of this evidence, a constant and exogenous probability of inspection sometimes is used in the theoretical literature for the sake of simplicity. However, given legal restrictions,

\footnotetext{
${ }^{22}$ See Block et al. (1981).

${ }^{23}$ See, among others, Besanko and Spulber (1989), Polo (1997), and Souam (2001).

${ }^{24}$ See, for example, Harrington (2003), (2004) and (2005).

${ }^{25}$ However, Motta and Polo (2003) begin their analysis by considering the policy parameters as exogenous. After that, they discuss the trade-off between the monitoring and prosecution rates, and determine the optimal level of those parameters, which will finally depend on an exogenous budget.

${ }^{26}$ Friederiszick and Maier-Rigaud (2007) argue that "surprise inspections are by far the most effective and sometimes the only means of obtaining the necessary evidence...."

${ }^{27}$ Council Regulation (EC) $\mathrm{N}^{o} 1 / 2003$, on implementation of the rules on competition laid down in Articles 81 and 82 of the Treaty, articles $20-22$.
} 
this policy is not used in practice, even though it may be more effective than other inspection policies.

\subsection{Some extensions toward the optimal enforcement in the network con- text}

We could extend the analysis in, at least, two ways. First, in the actual practice, the initial evidence that prompts competition authorities to adopt an inspection decision is supplied by customers or competitors. Anomalous prices may cause customers or competitors to suspect collusive behavior. Therefore, an enforcement policy described by a probability of inspection positively related with prices seems to be interesting and realistic.

That is, given the collusive network framework, more links will imply higher prices, and therefore a greater probability of inspection. Then, when a particular firm is calculating the probability of being caught, it takes into account who will be its partner in a collusive agreement. That is, the firm in consideration cares about not only how many links it has but also how many agreements its partner has. This asymmetry between firms may cause the network configuration to change.

The second extension is related to a more complex antitrust policy, e.g. a leniency program. In this situation, the current assumption about the competition authority's technology should be changed. Here, we are assuming that when the AT audits, it detects the firms involved in a market-sharing agreement without errors (and without cost). If we relax this assumption, then we allow the evidence which is reported by firms, in a leniency program, to have some value for the AT. Moreover, we must change the static setting toward a dynamic one, and therefore consider the network formation game.

\subsection{Other extensions}

\section{Stable Collusive Networks in the Asymmetric Context}

We extend the analysis to asymmetric situations, particularly, by assuming asymmetric markets. By proceeding in this way, we are nearer to realistic situations but farther from providing a generalization of the results. For that reason, we use an example where three firms operate in markets with different profitability.

\section{Example 5 The AT and Asymmetric Markets}

Consider the inverse demand function $P_{i}(Q)=A_{i} e^{-Q}$ and assume $A_{3}>A_{2}>A_{1}=1$. The set of configurations of stable networks is the same for all $\alpha \geq 0$. The presence of the AT implies more competition, though the network configuration remains unchanged. That is, 
1. The complete network is stable if $A_{3} \leq e(1-\alpha)-1$. And it is strong stable if $A_{3} \leq \frac{\left(e^{2}(1-\alpha)^{3}-1\right)}{e}-A_{2}$.

2. The empty network is stable when (i) $A_{2}>(e-1)-\alpha\left(e+A_{3}\right)$ and (ii) $A_{3}>$ $A_{2}(e-1)-\alpha\left(A_{2}+1\right)$

3. The three networks with two linked firms and one isolated firm are stable for different combinations of the parameter. For instance, the network with a single agreement between the firms in the larger markets is stable if and only if $A_{3} \leq A_{2}(e-1)-$ $\alpha\left(A_{2} e-1\right)$.

4. An incomplete collusive network is stable, for instance, the smallest market forms an agreement with each of the other two firms, when (i) $A_{2}(e-1)-\alpha A_{2}<A_{3} \leq$ $e(e-1)-\alpha e^{2}$ and (ii) $A_{2} \geq \frac{e+\alpha A_{3}}{e(1-\alpha)^{2}-1}$. Additionally, it is strongly stable if and only if $A_{3}+A_{2} \leq\left(e^{2}-1\right)+\alpha e^{2}\left(3 \alpha-\alpha^{2}-3\right)$

5. Fails to exist if (i) $A_{2}<(e-1)-\alpha\left(e+A_{3}\right)$; (ii) $A_{3}<A_{2}(e-1)-\alpha\left(A_{2}+1\right)$; and $A_{3} \geq e(e-1)-\alpha e^{2}$.

\section{Concluding Remarks}

We have characterized the stable collusive network that arises when firms form marketsharing agreements among themselves, in a symmetric oligopolistic setting when an antitrust authority exists.

In this network framework, the incentives to participate in a collusive agreement are weakened by the AT, because it reduces the net expected benefit from signing them. Under the presence of the AT, the expected penalties of forming illegal links appear, and they are positively related with the network configuration. This is because of two facts. First, firms, considering whether to sign an agreement, take into account the probability of being discovered rather than the probability of being inspected; and the first probability positively depends on the number of agreements each firm has signed. Second, the fine imposed by the AT on a guilty firm is equal to its total profits, which depends on the number of active firms in its home market and also on the number of active firms in all foreign markets in which the guilty firm does not collude. Consequently, the penalty will be greater as the number of active firms in those market is smaller, i.e., the number of links is larger. Thus, the penalty positively depends on the network configuration as a whole.

We have shown that, the pairwise stable network can be decomposed into a set of isolated firms and complete components of different sizes. However, when the AT exists, we cannot define a unique lower bound on the size of complete components because, now, it depends on each network configuration and on each probability of being inspected. In turn, this implies 
that, although the lower bound on the size of complete components may be greater, the set of isolated firms enlarges and finally, more structures that are competitive can be sustained through bilateral agreements.

We have also shown that, antitrust laws have a pro-competitive effect as they give firms in large alliances more incentives to cut their agreements at once. Therefore the empty network might arise as the only strongly stable network.

The network configurations in the asymmetric context are the same as when the antitrust authority does not exist; however, its presence reduces the space of profitable collusion because it imposes additional restrictions.

Although the optimal deterrence policy is beyond of the scope of the current paper, an important policy implication of the current formulation is that the organization of the illegal behavior matters. That is, the analysis of the optimal deterrence of market-sharing agreements has to take into account the organizational structure of collusive firms. Furthermore, without consideration of the effects of the organizational structure, empirical studies may overestimate the contribution of efforts devoted to investigate and prosecute collusive agreements. ${ }^{28}$

In this paper, we consider a relatively simple setting for analyzing the effect of the antitrust policy $\{\alpha, F(\Pi)\}$ on the structure of criminal behavior. Then, one can go from here in many directions. One of them is to consider the probability of inspection as a function of prices. This introduces some asymmetry among firms, and then the criminal network's configuration may change. Another extension to this paper is to introduce a more complex antitrust policy, e.g. a leniency program. In this way, we have to move towards a dynamic setting where the study of the network formation game becomes relevant.

\section{Appendix}

\section{Necessary conditions for pairwise stability}

Proof Lemma 1 Since $g$ is stable, when $g_{i j}=1$ the next two conditions simultaneously hold:

$$
\begin{aligned}
& (1-\alpha) \pi\left(n_{i}(g)\right) \geq \pi\left(n_{i}(g)+1\right)+\pi\left(n_{j}(g)+1\right)+\alpha \sum_{k: g_{i k}=0} \pi\left(n_{k}(g)\right) \\
& (1-\alpha) \pi\left(n_{j}(g)\right) \geq \pi\left(n_{j}(g)+1\right)+\pi\left(n_{i}(g)+1\right)+\alpha \sum_{k: g_{j k}=0} \pi\left(n_{k}(g)\right)
\end{aligned}
$$

\footnotetext{
${ }^{28}$ Some empiral papers that estimate the deterrent effect of the policy are, among others, Buccirossi and Spagnolo (2005), Connor (2006), Zimmerman and Connor (2005).
} 
Given that the profit function is decreasing in $n$, the following are a pair of necessary conditions that must be satisfied for the above inequalities to hold:

$$
\begin{aligned}
& \pi\left(n_{i}(g)\right)>\pi\left(n_{j}(g)+1\right) \\
& \pi\left(n_{j}(g)\right)>\pi\left(n_{i}(g)+1\right)
\end{aligned}
$$

From the first inequality $n_{i}(g)<n_{j}(g)+1$ and from the second one $n_{j}(g)<n_{i}(g)+1$ Hence:

$$
n_{j}(g)-1<n_{i}(g)<n_{j}(g)+1 \Leftrightarrow n_{i}(g)=n_{j}(g)
$$

That is

$$
n_{i}(g)=n_{j}(g) \equiv n(g)
$$

\section{Proof Lemma 2}

Part 1: If $g$ is stable then any component $g^{\prime} \in g$ is complete. Suppose $g^{\prime}$ is not complete. Then, there are three firms $i, j, l$ in the component such that $g_{i j}=g_{j l}=1$ and $g_{i l}=0$. Because $g$ is stable, then by Lemma $1 n_{i}(g)=n_{j}(g) \equiv n(g)$; also $n_{j}(g)=n_{l}(g) \equiv$ $n(g)$, then $n_{i}(g)=n_{j}(g)=n_{l}(g) \equiv n(g)$. By stability, we rewrite $J_{j}^{i}, J_{i}^{j}$, and $J_{j}^{l}$ as follow:

$$
\begin{aligned}
& \underbrace{\frac{\pi(n)}{\pi(n+1)}}_{A} \geq \underbrace{\frac{2}{(1-\alpha)}+\frac{\sum_{k: g_{i k}=0, i \neq k} \pi^{i}\left(n_{k}(g)\right)}{(1-\alpha) \pi(n+1)}}_{B} \text { for } i \neq k \\
& \frac{\alpha(n)}{\pi(n+1)} \geq \frac{2}{(1-\alpha)}+\frac{\sum_{k: g_{j k}=0, j \neq k} \pi^{j}\left(n_{k}(g)\right)}{(1-\alpha) \pi(n+1)} \text { for } j \neq k \\
& \frac{\alpha(n)}{\pi(n+1)} \geq \frac{2}{(1-\alpha)}+\frac{\sum_{k: g_{l k}=0, l \neq k} \pi^{l}\left(n_{k}(g)\right)}{(1-\alpha) \pi(n+1)} \text { for } l \neq k
\end{aligned}
$$

Given that $g_{i l}=0$, then one or both conditions hold:

$$
\begin{aligned}
& \underbrace{\frac{\pi(n-1)}{\pi(n)}}_{D}<\underbrace{\frac{2}{(1-\alpha)}+\frac{\alpha \sum_{k: g_{i k}=0, i \neq k} \pi^{i}\left(n_{k}(g)\right)}{(1-\alpha) \pi(n)}}_{E} \text { for } i \neq k ; \text { and } / \text { or } \\
& \frac{\pi(n-1)}{\pi(n)}<\frac{2}{(1-\alpha)}+\frac{\sum_{k: g_{l k}=0, l \neq k} \pi^{l}\left(n_{k}(g)\right)}{(1-\alpha) \pi(n)} \text { for } l \neq k
\end{aligned}
$$


By log-convexity, we can establish that:

$$
A \leq D
$$

From stability:

$$
B \leq A \leq D<E
$$

However given that profits are decreasing functions and given that the number of terms in $\sum_{k: g_{i k}=0} \pi^{i}\left(n_{k}\right)$ in $B$ and $E$ are different, we can say that:

$$
B>E
$$

This is a contradiction. Then $g^{\prime}$ must be a complete component.

The same logic applies for $l$.

Part 2: If $g$ is stable then the complete components must have different sizes. Take two firms $i, j$ in component $g^{\prime}$ and a firm $l$ in $g^{\prime \prime}$. Suppose, by contradiction, that $m\left(g^{\prime}\right)+1=m\left(g^{\prime \prime}\right)+1$. Therefore, we have $n_{i}(g)=n_{j}(g)=n_{l}(g) \equiv n$. The stability of $g$ implies that $J_{j}^{i} \geq 0$ and $J_{i}^{j} \geq 0$. That is:

$$
\begin{aligned}
& \underbrace{\frac{\pi(n)}{\pi(n+1)}}_{A} \geq \underbrace{\frac{2}{(1-\alpha)}+\frac{\sum_{k: g_{i k}=0, i \neq k} \pi^{i}\left(n_{k}(g)\right)}{(1-\alpha) \pi(n+1)}}_{B} \text { for } i \neq k \\
& \frac{\alpha(n)}{\pi(n+1)} \geq \frac{2}{(1-\alpha)}+\frac{\sum_{k: g_{j k}=0, j \neq k} \pi^{j}\left(n_{k}(g)\right)}{(1-\alpha) \pi(n+1)} \text { for } j \neq k
\end{aligned}
$$

For $i$ and/or $l$, one or both conditions hold:

$$
\begin{aligned}
& \underbrace{\frac{\pi(n-1)}{\pi(n)}}_{D}<\underbrace{\frac{2}{(1-\alpha)}+\frac{\alpha \sum_{k: g_{i k}=0, i \neq k} \pi^{i}\left(n_{k}(g)\right)}{(1-\alpha) \pi(n)}}_{E} \text { for } i \neq k \text {; and/or } \\
& \frac{\pi(n-1)}{\pi(n)}<\frac{2}{(1-\alpha)}+\frac{\sum_{k: g_{l k}=0, l \neq k} \pi^{l}\left(n_{k}(g)\right)}{(1-\alpha) \pi(n)} \text { for } l \neq k
\end{aligned}
$$

By log-convexity, we can establish that:

$$
A \leq D
$$


From stability conditions:

$$
B \leq A \leq D<E
$$

However, given that profits are decreasing functions and given that the number of terms in $\sum_{k: g_{i k}=0} \pi^{i}\left(n_{k}\right)$ in $B$ and $E$ are different, we can say that:

$$
B>E
$$

Nevertheless, it is a contradiction with the assumption that profits are log-convex and stability of $g$.

The same logic applies for

Proof Lemma 3 If $i \in g_{h}^{*}$ does not have incentives to cut a link with a firm inside its component, it is true that:

$$
\frac{\pi\left(N-m\left(g_{h}^{*}\right)\right)}{\pi\left(N-m\left(g_{h}^{*}\right)+1\right)}>\frac{2}{(1-\alpha)}+\frac{\alpha\left[\left(m\left(g_{l}\right)+1\right) \pi\left(N-m\left(g_{l}\right)\right)+\sum_{k: g_{i k}=0} \pi\left(n_{k}\right)\right]}{(1-\alpha) \pi\left(N-m\left(g_{h}^{*}\right)+1\right)}
$$

Assume by contradiction that $j \in g_{l}$ for $m\left(g_{l}\right)>m^{*}\left(g_{h}^{*}\right)$ has an incentive to cut a link with a firm inside its component. Then

$$
\frac{\pi\left(N-m\left(g_{l}\right)\right)}{\pi\left(N-m\left(g_{l}\right)+1\right)}<\frac{2}{(1-\alpha)}+\frac{\alpha\left[\left(m\left(g_{h}^{*}\right)+1\right) \pi\left(N-m\left(g_{h}^{*}\right)\right)+\sum_{k: g_{j k}=0} \pi\left(n_{k}\right)\right]}{(1-\alpha) \pi\left(N-m\left(g_{l}\right)+1\right)}
$$

When profits are decreasing in $n$, then $\operatorname{RHS}(10)>\operatorname{RHS}(11)$. By log-convexity assumption $\operatorname{LHS}(10)<\operatorname{LHS}(11)$. Therefore, if $i$ does not have an incentive to cut a link with a firm inside its component, $\operatorname{LHS}(10)>\operatorname{RHS}(10)$, then $\operatorname{LHS}(11)>\operatorname{RHS}(11)$, which contradicts (11)

Proof Proposition 1 Lemmas 1 and 2 provide necessary conditions on stability. Let us consider the sufficient part. Consider a network $g$ that can be decomposed into a set of isolated firms and distinct complete components, $g_{1}, \ldots, g_{L}$ of different sizes $m\left(g_{l}\right) \neq m\left(g_{l^{\prime}}\right), \forall l, l^{\prime}$. Isolated players have no incentive to create a link with another isolated one. As long as a firm $i$, that belongs to the smallest component, does not have incentives to cut a link with a firm inside its component, then, by Lemma 3, no firm inside a component has incentives to cut a link. Additionally, given that $m\left(g_{l}\right) \neq m\left(g_{l^{\prime}}\right), \forall l, l^{\prime}$, there do not exist two firms belonging to different components that have an incentive to form an agreement between themselves. 
Proof Proposition $2 \Rightarrow$ Consider a pairwise strong Nash equilibrium $s^{*}$. Given that any strongly pairwise stable network is pairwise stable, $g\left(s^{*}\right)$ can be decomposed into a set of isolated firms and complete components where no isolated firm wants to form a link with another isolated one and (10) holds . But assume, by contradiction, that some component $g_{l}$ does not satisfy the condition $(1-\alpha)^{m} \pi(N-m+1) \geq \pi(N)+(m-1) \pi(N-m+2)+$ $\sum \pi\left(n_{k}\right)\left(1-(1-\alpha)^{m}\right) \forall m=m\left(g_{l}\right)$. Then $s^{*}$ is not a Nash equilibrium because any firm $i$ in $g_{l}$ has a profitable deviation by choosing $s_{i}^{\prime}=\emptyset$.

$\Longleftarrow$ Assume network $g$ can be decomposed into a set of isolated firms and complete components of different sizes, where inequality (10) holds. Also assume that $(1-\alpha)^{m} \pi(N-m+1) \geq$ $\pi(N)+(m-1) \pi(N-m+2)+\sum \pi\left(n_{k}\right)\left(1-(1-\alpha)^{m}\right)$ holds for all $m=m\left(g_{l}\right)$. We will show that the following strategies form a pairwise strong Nash equilibrium. For firm $i \in g_{l}$ it announces $s_{i}^{*}=\left\{j \mid j \in g_{l}, j \neq i\right\}$, however, if $i$ is isolated, it announces $s_{i}^{*}=\emptyset$. Hence,

a) No isolated firm $i$ has an incentive to create a link with another firm $j$, as $i \notin s_{j}^{*}$.

b) $\operatorname{As}(1-\alpha)^{m} \pi(N-m+1) \geq \pi(N)+(m-1) \pi(N-m+2)+\sum \pi\left(n_{k}\right)\left(1-(1-\alpha)^{m}\right)$ holds for all $m=m\left(g_{l}\right)$, the firm has no incentive to destroy all its $m$ links. However, we must consider the firm's incentives to cut a subset of them. Let us assume it has an incentive to delete a strict subset of its links, hence, it chooses to delete $h$ links because

$$
(1-\alpha)^{h} \pi(N-m+1)<\pi(N-m+1+h)+h \pi(N-m+2)+\sum \pi\left(n_{k}\right)\left(1-(1-\alpha)^{h}\right)
$$

Given that $h \geq 1$, then

$$
\pi(N-m+1+h)+h \pi(N-m+2) \leq(h+1) \pi(N-m+2)
$$

Since we are considering a strict subset of links, then $h<m-1$ and $h+1<m-1$, hence

$$
(h+1) \pi(N-m+2)<(m-1) \pi(N-m+2)
$$

Therefore

$$
(1-\alpha)^{m} \pi(N-m+1)<(1-\alpha)^{h} \pi(N-m+1)<(m-1) \pi(N-m+2)
$$

that contradicts our hypothesis.

c) No firm $i \in g_{l}$ has an incentive to create a link with firm $j \in g_{l^{\prime}}$ as $i \notin s_{j}^{*}$. Moreover, as $m\left(g_{l}\right) \neq m\left(g_{l^{\prime}}\right)$ for all $l \neq l^{\prime}$, no pair of firms $i \in g_{l}$ and $j \in g_{l^{\prime}}$ has an incentive to create a new link between them.

d) As $(1-\alpha)^{m} \pi(N-m+1) \geq \pi(N)+(m-1) \pi(N-m+2)+\sum \pi\left(n_{k}\right)\left(1-(1-\alpha)^{m}\right)$ holds for all $m=m\left(g_{l}\right)$, when $m>3$, no pair of firms have incentives to delete all their links nor a subsets of their agreements and to form a link between them. Let us assume, by 
contradiction, a pair of firms, $i \in m$ and $j \in m^{\prime}$, has incentive to destroy all their $m$ and $m^{\prime}$ links each and form a link between them. For firm $i$, this is

$$
\begin{aligned}
& (1-\alpha)^{m-2} \pi(N-m+1) \\
< & \pi(N-1)+(m-1) \pi(N-m+2)+\left(m^{\prime}-1\right) \pi\left(N-m^{\prime}+2\right)+ \\
+ & \sum_{k \neq j \neq i, g_{i k=0},} \pi\left(n_{k}\right)-(1-\alpha)^{m-2}\left[\sum_{k \neq j \neq i, g_{i k=0},} \pi\left(n_{k}\right)+m^{\prime} \pi\left(N-m^{\prime}+1\right)\right]
\end{aligned}
$$

Given that, the LHS(12)>LHS(9) and by straightforward computations we can show that $\operatorname{RHS}(9)>\operatorname{RHS}(12)$, when condition(9) holds then LHS(12)>RHS(12), which contradicts (12).

Calculation details of Example 1 For alliances of sizes 2, we must check stability condition (8). That is, whether $\frac{\pi(6)}{\pi(7)}>\frac{2}{(1-\alpha)}+\frac{\alpha(3 \pi(5)+2 \pi(7))}{(1-\alpha) \pi(7)}$ holds,

$$
e>\frac{2}{(1-\alpha)}+\frac{\alpha\left(3 e^{-5}+2 e^{-7}\right)}{(1-\alpha) e^{-7}}=2.6710
$$

Then (8) holds for any firm belonging to a smaller component.

From Lemma 3 and given the last inequality, we know that any firm inside the bigger component does not want to cut a link. A firm in the bigger component has an incentive to maintain a link as long as $\frac{\pi(5)}{\pi(6)}>\frac{2}{(1-\alpha)}+\frac{\alpha(2 \pi(6)+2 \pi(7))}{(1-\alpha) \pi(6)}$. That is:

$$
e>\frac{2}{(1-\alpha)}+\frac{2 \alpha\left(e^{-6}+e^{-7}\right)}{(1-\alpha) e^{-6}}=2.1214
$$

And for isolated firms, it is true that $\frac{\pi(6)}{\pi(7)}<\frac{2}{(1-\alpha)}+\frac{\alpha(3 \pi(5)+2 \pi(6))}{(1-\alpha) \pi(7)}$. That is:

$$
e<\frac{2}{(1-\alpha)}+\frac{\alpha\left(3 e^{-5}+2 e^{-6}\right)}{(1-\alpha) e^{-7}}=2.7591
$$

Proof Proposition $3 \quad(\Longrightarrow)$ If $g^{c}$ is pairwise stable then

$$
(1-\alpha) \pi(1) \geq 2 \pi(2)
$$

By rewriting the last condition, we get $\alpha \leq \alpha^{c}=1-\frac{2 \pi(2)}{\pi(1)}$.

$(\Longleftarrow)$ If $\alpha \leq \alpha^{c}=1-\frac{2 \pi(2)}{\pi(1)}$, then $(1-\alpha) \pi(1) \geq 2 \pi(2)$. Therefore, $g^{c}$ will be pairwise stable.

Proof Proposition 4 Assume that $N \geq 3$. 
$(\Longrightarrow)$ If $g^{e}$ is pairwise stable then,

$$
(1-\alpha)^{2}[\pi(N-1)+(N-2) \pi(N)]<\pi(N)+\pi(N)+(N-2) \pi(N)
$$

and, by straightforward calculation,

$$
\alpha>1-\left[\frac{N \pi(N)}{[\pi(N-1)+(N-2) \pi(N)]}\right]^{\frac{1}{2}}=\alpha_{e}(N)
$$

$(\Longleftarrow)$ If $\alpha>\alpha_{e}(N)$, then (14) holds. Therefore, $g^{e}$ is pairwise stable.

Proof Proposition 5 For simplicity, let us assume two complete components $g_{1}$ and $g_{2}$. For each firm $i \in g_{1}, n_{1}$ is the number of active firms in its market, and for each firm $j$ $\in g_{2}, n_{2}$ is the number of active firms in its market.

Let us define $\alpha^{*}\left(n_{i}\right):=\frac{\pi\left(n_{i}-1\right)-2 \pi\left(n_{i}\right)}{\pi\left(n_{i}-1\right)+\sum_{k \neq j, g i=0} \pi\left(n_{k}\right)}$.

We are interested to know whether $\alpha^{*}\left(n_{1}\right) \lessgtr \alpha^{*}\left(n_{2}\right)$. That is,

$$
\frac{\pi\left(n_{1}-1\right)-2 \pi\left(n_{1}\right)}{\pi\left(n_{1}-1\right)+\left(N-n_{2}+1\right) \pi\left(n_{2}\right)} \lessgtr \frac{\pi\left(n_{2}-1\right)-2 \pi\left(n_{2}\right)}{\pi\left(n_{2}-1\right)+\left(N-n_{1}+1\right) \pi\left(n_{1}\right)}
$$

By solving the last expression, we get

$$
\begin{aligned}
& \left(N-n_{1}+1\right) \pi\left(n_{1}\right) \pi\left(n_{1}-1\right)-2 \pi\left(n_{1}\right) \pi\left(n_{2}-1\right)-2\left(N-n_{1}+1\right)\left[\pi\left(n_{1}\right)\right]^{2} \lessgtr \\
& \left(N-n_{2}+1\right) \pi\left(n_{2}\right) \pi\left(n_{2}-1\right)-2 \pi\left(n_{2}\right) \pi\left(n_{1}-1\right)-2\left(N-n_{2}+1\right)\left[\pi\left(n_{2}\right)\right]^{2}
\end{aligned}
$$

In order to decide the sense of the inequality, we rearrange the above expression into the following two parts:

$$
\begin{gathered}
\left(N-n_{1}+1\right) \pi\left(n_{1}\right)\left[\pi\left(n_{1}-1\right)-2 \pi\left(n_{1}\right)\right] \lessgtr\left(N-n_{2}+1\right) \pi\left(n_{2}\right)\left[\pi\left(n_{2}-1\right)-2 \pi\left(n_{2}\right)\right] \\
\pi\left(n_{1}\right) \pi\left(n_{2}-1\right) \lessgtr \pi\left(n_{2}\right) \pi\left(n_{1}-1\right)
\end{gathered}
$$

If $n_{1}>n_{2}$, then (i) $\left(N-n_{1}+1\right)<\left(N-n_{2}+1\right)$; (ii) by Property $1, \pi\left(n_{1}\right)<\pi\left(n_{2}\right)$; (iii) by Property $2,\left[\pi\left(n_{1}-1\right)-2 \pi\left(n_{1}\right)\right]<\left[\pi\left(n_{2}-1\right)-2 \pi\left(n_{2}\right)\right]$.

Therefore,

$$
\left(N-n_{1}+1\right) \pi\left(n_{1}\right)\left[\pi\left(n_{1}-1\right)-2 \pi\left(n_{1}\right)\right]<\left(N-n_{2}+1\right) \pi\left(n_{2}\right)\left[\pi\left(n_{2}-1\right)-2 \pi\left(n_{2}\right)\right]
$$

Additionally, if $n_{1}>n_{2}$, then, by Property $3, \frac{\pi\left(n_{2}-1\right)}{\pi\left(n_{2}\right)}>\frac{\pi\left(n_{1}-1\right)}{\pi\left(n_{1}\right)}$

Hence, 


$$
\pi\left(n_{1}\right) \pi\left(n_{2}-1\right)>\pi\left(n_{2}\right) \pi\left(n_{1}-1\right)
$$

Therefore, if, $n_{1}>n_{2}$, by (15) and (16), then

$$
\frac{\pi\left(n_{1}-1\right)-2 \pi\left(n_{1}\right)}{\pi\left(n_{1}-1\right)+\left(N-n_{2}+1\right) \pi\left(n_{2}\right)}<\frac{\pi\left(n_{2}-1\right)-2 \pi\left(n_{2}\right)}{\pi\left(n_{2}-1\right)+\left(N-n_{1}+1\right) \pi\left(n_{1}\right)}
$$

or, in other words, if $n_{1}>n_{2}$, then

$$
\alpha^{*}\left(n_{1}\right)<\alpha^{*}\left(n_{2}\right)
$$

Proof Proposition 6 By Claim 1, we know that, at $\alpha=\alpha^{c}, g^{e}$ and $g^{c}$ are pairwise stable.

Now, we must check, for $\alpha=\alpha^{c}$, whether a firm $i$ has incentive to form an additional agreement when $n \neq 1$ and $n \neq N$.

Therefore, we must verify whether $J_{j}^{i} \lessgtr 0$, that is,

$$
\pi(n-1)-2 \pi(n) \lessgtr \alpha\left(\pi(n-1)+\sum_{k \neq j, g_{k i}=0} \pi\left(n_{k}\right)\right)
$$

At $\alpha=\alpha^{c}$, the above expression is

$$
\pi(n-1)-2 \pi(n) \lessgtr\left[1-\frac{2 \pi(2)}{\pi(1)}\right]\left(\pi(n-1)+\sum_{k \neq j, g_{k i}=0} \pi\left(n_{k}\right)\right)
$$

After some calculations, we obtain

$$
2[\pi(n-1) \pi(2)-\pi(n) \pi(1)] \lessgtr \sum_{k \neq j, g_{k i}=0} \pi\left(n_{k}\right)[\pi(1)-2 \pi(2)]
$$

By Property $2, \pi(1)-2 \pi(2)>0$, and by Property $3,[\pi(n-1) \pi(2)-\pi(n) \pi(1)]<0$. Therefore, at $\alpha=\alpha^{c}$,

$$
J_{j}^{i}<0
$$

Proof Proposition 7 The partial derivative of (9) respect to $\alpha$ is:

$$
-(m+1)\left[\pi(N-m+1)+\sum \pi\left(n_{k}\right)\right](1-\alpha)^{m}
$$


That is, as $\alpha$ increases, the incentive to maintain links decreases.

Now, we must check whether (17) is large for firms in large component. Without loss of generality, assume that there are two components whose sizes are $m_{1}+1$ and $m_{2}+1$, such that $m_{1}>m_{2}$. After some computations, we can verify that, for a sufficiently high $m$, the following holds:

$-\left(m_{1}+1\right)\left[\pi\left(N-m_{1}+1\right)+m_{2} \pi\left(N-m_{2}+1\right)\right](1-\alpha)^{m_{1}}<-\left(m_{2}+1\right)\left[\pi\left(N-m_{2}+1\right)+m_{1} \pi\left(N-m_{1}+1\right.\right.$

Computations for Table $1(\alpha=0.04)$ and Table 2: pairwise stability

Empty Network $p(\alpha)=(1-\alpha)^{2} e^{-4}-2 e^{-5}-3 e^{-5}\left(1-(1-\alpha)^{2}\right)$

$p(\alpha)=0$, Solution is: $6.4913 \times 10^{-2}$

\section{$\mathrm{N}=5$, three firms isolated and two linked}

For a linked firm, we must check the sign of:

$$
\begin{aligned}
& p(\alpha)=(1-\alpha)^{2} e^{-4}-2 e^{-5}-3 e^{-5}\left(1-(1-\alpha)^{2}\right) \\
& p(\alpha)=0, \text { Solution is: } 6.4913 \times 10^{-2}
\end{aligned}
$$

For an isolated firm, we must check the sign of:

$$
\begin{aligned}
& p(\alpha)=(1-\alpha)^{2} e^{-4}-2 e^{-5}-\left(e^{-5}+2 e^{-4}\right)\left(1-(1-\alpha)^{2}\right) \\
& p(\alpha)=0, \text { Solution is:4. } 0031 \times 10^{-2}
\end{aligned}
$$

\section{$\mathrm{N}=5$, two firms isolated and one component of three firms linked}

For firms in the complete component, we must check the sign of:

$$
\begin{aligned}
& p(\alpha)=(1-\alpha) e^{-3}-2 e^{-4}-2 \alpha e^{-5} \\
& p(\alpha)=0, \text { Solution is: } \frac{e^{-3}-2 e^{-4}}{e^{-3}+2 e^{-5}}=0.20795
\end{aligned}
$$

For an isolated firm, we must check the sign of:

$$
\begin{aligned}
& p(\alpha)=(1-\alpha)^{2} e^{-4}-2 e^{-5}-3 e^{-3}\left(1-(1-\alpha)^{2}\right) \\
& p(\alpha)=0, \text { Solution is: } 1.4537 \times 10^{-2}
\end{aligned}
$$

$\mathrm{N}=5$, one isolated firm and one component of four firms linked For firms in the complete component, we must check the sign of:

$$
\begin{aligned}
& p(\alpha)=(1-\alpha) e^{-2}-2 e^{-3}-\alpha e^{-5} \\
& p(\alpha)=0, \text { Solution is: } \frac{e^{-2}-2 e^{-3}}{e^{-2}+e^{-5}}=0.25171
\end{aligned}
$$

The isolated firm does not have an incentive to form any agreement for all $\alpha$. 
$\mathrm{N}=5$, two complete components: one of them composed of two firms and the other one of three firms.

Condition for maintaining a link in the complete component of two firms:

$$
\begin{aligned}
& p(\alpha)=(1-\alpha)^{2} e^{-4}-2 e^{-5}-3 e^{-3}\left(1-(1-\alpha)^{2}\right) \\
& p(\alpha)=0, \text { Solution is: } 1.4537 \times 10^{-2}
\end{aligned}
$$

Condition for maintaining a link in the complete component of three firms:

$$
\begin{aligned}
& p(\alpha)=(1-\alpha) e^{-3}-2 e^{-4}-2 \alpha e^{-5} \\
& p(\alpha)=0, \text { Solution is: } \frac{e^{-3}-2 e^{-4}}{e^{-3}+2 e^{-5}}=0.20795
\end{aligned}
$$

$\mathbf{N}=5$, Complete Network Condition for maintaining a link in the complete component of five firms:

$$
\begin{aligned}
& p(\alpha)=(1-\alpha) e^{-1}-2 e^{-2} \\
& p(\alpha)=0, \text { Solution is: } \frac{1}{e^{-1}}\left(e^{-1}-2 e^{-2}\right)=0.26424
\end{aligned}
$$

Computations for Table $1(\alpha=0.04)$ and Table 3: pairwise strong stability (ss)

Condition ss when $\alpha=0 \quad p(m)=e^{-(5-m+1)}-e^{-5}-(m-1) e^{-(5-m+2)}$

for $m=2$ and for $m=3, p(m)>0$

\section{Condition ss when $\alpha \neq 0$}

i. $\alpha \in\left(0 ; 1.4537 \times 10^{-2}\right]$

for $\mathrm{m}=2$

$p(m, \alpha)=(1-\alpha)^{m} e^{-(5-m+1)}-e^{-5}-(m-1) e^{-(5-m+2)}-\left(1-(1-\alpha)^{m}\right) 3 e^{-3}$

$p\left(2,1.4537 \times 10^{-2}\right)=1.4253 \times 10^{-7}$

for $\mathrm{m}=3$

$p(m, \alpha)=(1-\alpha)^{m} e^{-(5-m+1)}-e^{-5}-(m-1) e^{-(5-m+2)}-\left(1-(1-\alpha)^{m}\right) 2 e^{-4}$

$p\left(3,1.4537 \times 10^{-2}\right)=2.7036 \times 10^{-3}$

for $\mathrm{m}=4$

$p(m, \alpha)=(1-\alpha)^{m} e^{-(5-m+1)}-e^{-5}-(m-1) e^{-(5-m+2)}-\left(1-(1-\alpha)^{m}\right) e^{-5}$

$p\left(4,1.4537 \times 10^{-2}\right)=-2.8847 \times 10^{-2}$

for $\mathrm{m}=5$

$p(m, \alpha)=(1-\alpha)^{m} e^{-(5-m+1)}-e^{-5}-(m-1) e^{-(5-m+2)}$

$p\left(5,1.4537 \times 10^{-2}\right)=-0.20617$

ii. $\alpha \in\left(1.4537 \times 10^{-2} ; 4.0031 \times 10^{-2}\right]$ 
for $m=3$

$p(m, \alpha)=(1-\alpha)^{m} e^{-(5-m+1)}-e^{-5}-(m-1) e^{-(5-m+2)}-\left(1-(1-\alpha)^{m}\right) 2 e^{-5}$

$p\left(3,4.0031 \times 10^{-2}\right)=-8.7952 \times 10^{-4}$

check claim ii. table 2

$p(m, \alpha)=(1-\alpha)^{m} e^{-(5-m+1)}$

$p\left(3,4.0031 \times 10^{-2}\right)=4.4044 \times 10^{-2}$

$p(m, \alpha)=e^{-5}+(m-1) e^{-(5-m+2)}+\left(1-(1-\alpha)^{m}\right) 2 e^{-5}$

$p\left(3,4.0031 \times 10^{-2}\right)=4.4924 \times 10^{-2}$

for $\mathrm{m}=4$

$p(m, \alpha)=(1-\alpha)^{m} e^{-(5-m+1)}-e^{-5}-(m-1) e^{-(5-m+2)}-\left(1-(1-\alpha)^{m}\right) e^{-5}$

$p\left(4,4.0031 \times 10^{-2}\right)=-4.2183 \times 10^{-2}$

iii. $\alpha \in\left(4.0031 \times 10^{-2} ; 6.4913 \times 10^{-2}\right]$

for $\mathrm{m}=3$

$p(m, \alpha)=(1-\alpha)^{m} e^{-(5-m+1)}-e^{-5}-(m-1) e^{-(5-m+2)}-\left(1-(1-\alpha)^{m}\right) 2 e^{-5}$

$p\left(3,6.491 \times 10^{-2}\right)=-5.119 \times 10^{-3}$

for $\mathrm{m}=2$

$p(m, \alpha)=(1-\alpha)^{m} e^{-(5-m+1)}-e^{-5}-(m-1) e^{-(5-m+2)}-\left(1-(1-\alpha)^{m}\right) 3 e^{-5}$

$p\left(2,6.491 \times 10^{-2}\right)=1.8438 \times 10^{-7}$

iv. $\alpha \in\left(6.4913 \times 10^{-2} ; 0.20795\right]$

for $\mathrm{m}=3$

$p(m, \alpha)=(1-\alpha)^{m} e^{-(5-m+1)}-e^{-5}-(m-1) e^{-(5-m+2)}-\left(1-(1-\alpha)^{m}\right) 2 e^{-5}$

$p(3,0.20795)=-2.5411 \times 10^{-2}$ 


\section{References}

[1] Aumann, R. and Myerson, R. 1988. Endogenous formation links between players and coalitions: an application of the Shapley value. In Roth, A. The Shapley Value. Cambridge University Press, Cambridge, United Kingdom, 175-191.

[2] Ballester, C., Calvó-Armengol, A. and Zenou, Y., 2006. Who's who in networks. Wanted: the key player. Econometrica 74, 1403-1417.

[3] Becker, G., 1968. Crime and Punishment: An economic approach. Journal of Political Economy 76, 169-217.

[4] Belleflamme, P. and Bloch, F. 2004. market-sharing agreements and collusive networks. International Economic Review 45, 387-411.

[5] Besanko, D. and Spulber, D., 1989. Antitrust enforcement under asymmetric information. The Economic Journal 99, 408-425.

[6] and , 1990. Are Treble Damages Neutral? Sequential Equilibrium and Private Antitrust Enforcement. American Economic Review 80, 870-887.

[7] Block, M. et al, 1981. The deterrent effect of antitrust enforcement. Journal of Political Economy 89, 429-445.

[8] Buccirossi, P. and Spagnolo, G., 2005. Optimal Fines in the era of whistle-blowers: should price fixers still go to prison?Working paper.

[9] Calvó-Armengol, A. and Zenou, Y., 2003. Social networks and crime decisions: the role of social structure in facilitating delinquent behavior. IUI, The Research Institute of Industrial Economics

[10] Chen, Z. and Rey,P., 2007. On the design of Leniency Programs.

[11] Connor, J., 2006. Optimal deterrence and private international cartels. Department of Agricultural Economics, Purdue University. Working paper.

[12] D'Aspremont, C et al, 1983. On the stability of Collusive Price Leadership. Canadian Journal of Economics 16, 17-25.

[13] Deneckere, R. and Whinston, M., 1990. Multimarket contact and collusive behavior. Rand Journal of Economics 21, 1-26.

[14] Dutta, B. and Mutuswami, S., 1997. Stable Networks. Journal of Economic Theory 76, 322-344. 
[15] Frezal, S., 2006. On optimal cartel deterrence policies. International Journal of Industrial Organization 24, 1231-1240.

[16] Friederiszick, H. and Maier-Rigaud, F., 2007. The role of economics in the cartel detection in Europe. In D.Schmidtchen, M.Albert and S.Voigt (eds.), The more economic approach in the European Competition Law, Mohr Siebeck, Tübingen.

[17] Goyal, S., 1993. Sustainable Communications Networks. Tinbergen Institute Discussion Paper TI 93-250.

[18] - and Joshi, S., 2003. Networks of Collaboration in Oligopoly. Games and Economic Behavior 43, 57-85.

[19] — and Moraga, J.L., 2001. R\&D Networks. Rand Journal of Economics 32, 686-707.

[20] Harrington, Jr.,J.E., 2003. Some implications of antitrust laws of cartel pricing. Economics Letters 79, 377-383.

[21] Harrington, Jr.,J.E., 2004. Cartel Pricing Dynamics in the Presence of an Antitrust Authority. Rand Journal of Economics 35, 651-673

[22] Harrington, Jr.,J.E., 2005. Optimal Cartel Pricing in the. Presence of an Antitrust Authority. International Economic Review 46, 145-169

[23] Jackson, M. and A. van den Nouweland, 2005. Strongly stable networks. Games and Economic Behavior 51, 420-444.

[24] and Wolinsky, A., 1996. A strategic model of social and economic networks. Journal of Economic Theory 71, 44-74.

[25] Kühn, K.-U., 2001. Fighting collusion by regulating communication between firms. Economic Policy, 32, 169-204.

[26] LaCasse, C.,1995. Bid Rigging and the Threat of Government Prosecution. Rand Journal of Economics 26, 398-417

[27] Lee, L., 1980. Some models of antitrust enforcement. Southern Economic Journal 47, 147-155.

[28] Motta, M., 2004. Competition Policy: Theory and Practice. Cambridge University Press.

[29] and Polo, 2003. Leniency Programs and Cartel Prosecution. International Journal of Industrial Organization 21, 347-379. 
[30] Myerson, R.B., 1991. Game theory: Analysis of conflict. Cambridge, MA: Harvard University Press.

[31] Mitchell Polinsky, A. and Shavell, S., 2000. The economic theory of public enforcement of law. Journal of Economic Literature 38, 45-76.

[32] Polo, M., 1997. The Optimal Prudential Deterrence of Price Fixing Agreements. IGER, wp. $\mathrm{N}^{o} 120$

[33] Rey, P., 2002. Towards a Theory of Competition Policy. IDEI, University of Toulouse.

[34] Scherer, F. and Ross, D., 1990. Industrial Market Structure and Economic Performance, 3rd. Ed. Boston: Houghton-Mifflin.

[35] Smith, W.J. and Waughan, M.B., 1986. Economic welfare, price and profit: the deterrent effect of alternative antitrust regimes. Economic Inquiry 24, 615-629

[36] Souam, S., 2001. Optimal antirust policy under different regimes of fines. International Journal of Industrial Organization 19, 1-26.

[37] Spagnolo, G., 2000. Optimal Leniency Programs. Fondazione Eni Enrico Mattei, wp. $\mathrm{N}^{\circ} 42 / 2000$

[38] Stigler, G., 1950. Monopoly and Oligopoly by Merger. American Economic Review 40, 23-34.

[39] Vives, X., 1991. Precios y Oligopolio. Antoni Bosch, editor and Fundación ICO.

[40] Zimmerman, J. and Connor, J., 2005. Determinants of cartel duration: a cross-sectional study of modern private international cartels. Department of Agricultural Economics, Purdue University. Working paper. 